Published in final edited form as:

J Org Chem. 2005 April 29; 70(9): 3343-3352. doi:10.1021/jo0482211.

\title{
Development and Comparison of the Substrate Scope of Pd- Catalysts for the Aerobic Oxidation of Alcohols
}

\author{
Mitchell J. Schultz, Steven S. Hamilton, David R. Jensen, and Matthew S. Sigman \\ Department of Chemistry, University of Utah, 315 South 1400 East, Salt Lake City, Utah 84112 \\ $-8500$
}

Abstract

Broad Scope, 25 to $60{ }^{\circ} \mathrm{C}$

0.1 to $1 \mathrm{~mol} \%$ Catalyst

$\mathrm{O}_{2}$ or Air

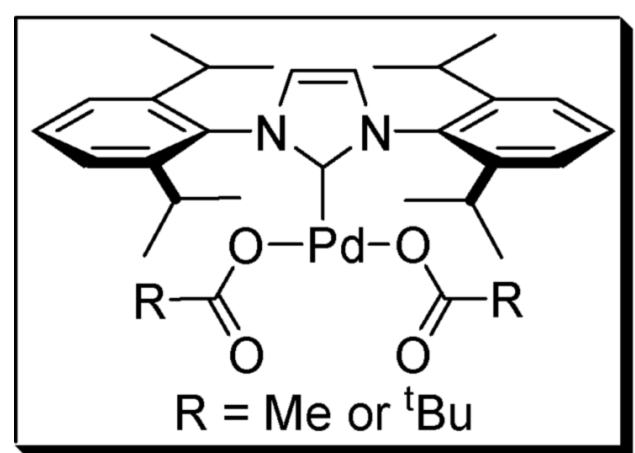

Broad Scope, $25^{\circ} \mathrm{C}$

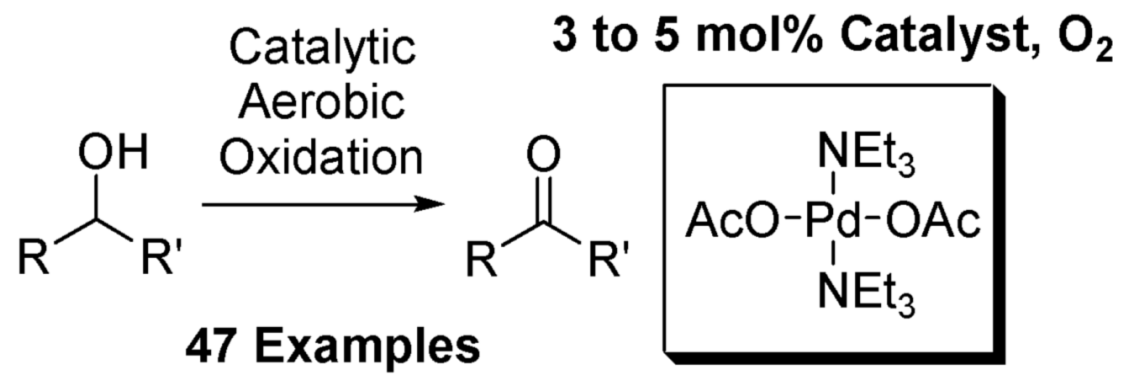

Three catalysts for aerobic oxidation of alcohols are discussed and the effectiveness of each is evaluated for allylic, benzylic, aliphatic, and functionalized alcohols. Additionally, chiral nonracemic substrates as well as chemoselective and diastereoselective oxidations are investigated. In this study, the most convenient system for the Pd-catalyzed aerobic oxidation of alcohols is $\mathrm{Pd}(\mathrm{OAc})_{2}$ in combination with triethylamine. This system functions effectively for the majority of alcohols tested and uses mild conditions ( 3 to $5 \mathrm{~mol} \%$ of catalyst, room temperature). $\mathrm{Pd}(\mathrm{IiPr})(\mathrm{OAc})_{2}\left(\mathrm{H}_{2} \mathrm{O}\right)(\mathbf{1})$ also successfully oxidizes the majority of alcohols evaluated. This system has the advantage of significantly lowering catalyst loadings but requires higher temperatures $(0.1$ to $1 \mathrm{~mol} \%$ of catalyst, $\left.60{ }^{\circ} \mathrm{C}\right)$. A new catalyst is also disclosed, $\mathrm{Pd}(\mathrm{IiPr})(\mathrm{OPiv})_{2}(2)$. This catalyst operates under very mild conditions ( $1 \mathrm{~mol} \%$, room temperature, and air as the $\mathrm{O}_{2}$ source) but with a more limited substrate scope.

\section{Introduction}

The oxidation of alcohols to carbonyl compounds is an essential functional group transformation in organic synthesis. Countless methods have been developed to perform this

(C) Copyright 2005 by the American Chemical Society

E-mail: sigman@chem.utah.edu.

Supporting Information Available: Experimental procedures and characterization data. This material is available free of charge via the Internet at http://pubs.acs.org. 
reaction, with the most popular represented by the Collins, ${ }^{1}$ Dess-Martin, ${ }^{2}$ Jones, ${ }^{3}$ Moffatt, ${ }^{4}$ Parikh-Doering, ${ }^{5}$ pyridinium chlorochromate (PCC) ${ }^{6}$ pyridinium dichromate (PDC), ${ }^{7}$ and Swern ${ }^{8}$ oxidations. These oxidations have served the organic synthesis community well as highly versatile and robust methods. Unfortunately, most of these suffer from the use of stoichiometric toxic reagents, cryogenic conditions, and/or the production of copious amounts of waste. An alternative, more practical approach is the use of a catalyst in combination with a stoichiometric terminal oxidant. An excellent example of this is the use of catalytic tetrapropylammonium perruthenate (TPAP) with stoichiometric $N$-methylmorpho-line (NMO) for the oxidation of alcohols. ${ }^{9}$ While this system has proven very useful for the oxidation of a wide variety of alcohols, the use of stoichiometric NMO is not ideal. ${ }^{10}$

An attractive alternative terminal oxidant is molecular oxygen because it is readily available, inexpensive, and produces benign stoichiometric byproducts $\left(\mathrm{H}_{2} \mathrm{O}_{2}\right.$ and/or $\left.\mathrm{H}_{2} \mathrm{O}\right)$. Due to these attributes, the development of catalysts for the aerobic oxidation of alcohols has been explored by using a diverse scope of metals which include $\mathrm{Mn},{ }^{11} \mathrm{Fe},{ }^{12} \mathrm{Ru},{ }^{13} \mathrm{Co},{ }^{14} \mathrm{Cu},{ }^{15} \mathrm{Pt},{ }^{16} \mathrm{Zn}$, ${ }^{17} \mathrm{Rh},{ }^{18} \mathrm{~V},{ }^{19} \mathrm{Ce},{ }^{20} \mathrm{Ni},{ }^{21} \mathrm{Pd},{ }^{22,23}$ and bimetallic systems. ${ }^{24}$ While many of these systems are synthetically useful, several drawbacks remain including the use of high catalyst loadings, forcing conditions, and/or lack of substrate scope. With the hope of addressing these issues, we have investigated the development of new $\mathrm{Pd}$ (II)-catalysts for the aerobic oxidation of alcohols. 25

Significant effort has been afforded to the development of Pd-catalysts for the aerobic alcohol oxidations. ${ }^{26-28}$ Of these reports, Uemura's pyridine/Pd(OAc) $)_{2}$ system $^{29}$ and Sheldon's phananthroline $/ \mathrm{Pd}(\mathrm{OAc})_{2}$ system $^{30}$ under aqueous conditions serve as benchmarks in the development of new catalysts: Uemura's primarily due to the simplicity of the procedure and Sheldon's due to the effective use of low loadings of the homogeneous catalyst. ${ }^{31}$ However, improved catalyst systems are desirable where a combination of lower catalyst loadings, lower levels of oxygen, and milder temperatures can be used. These improvements would potentially allow for applications in various areas including industrial oxidations and oxidations of complex targets.

In this regard, we have recently reported two catalyst systems for the palladium-catalyzed aerobic oxidation of alcohols. In the first system, a mixture of $\mathrm{Pd}(\mathrm{OAc})_{2}$ and triethylamine (TEA) was used to successfully oxidize a broad scope of alcohols at room temperature. ${ }^{32}$ After disclosing this initial study, we used data from mechanistic studies performed by several groups including our own on aerobic alcohol oxidations to design and develop a highly active catalyst using an $\mathrm{N}$-heterocyclic carbene (NHC) as the ligand for Pd, and acetate as both the anionic ligand and the internal base for successful oxidation. 33,34

While these two catalyst systems provided significant advances in both practicality (room temperature and air atmosphere) and activity (up to 1000 turnovers) for the Pd-catalyzed aerobic oxidation of alcohols, developing a catalyst system that can combine the use of low temperatures, low catalyst loadings, and an air atmosphere is desirable. Also, the application of Pd-catalysis to the oxidation of more complex substrates bearing alcohols has been lacking. Herein, we report on the development of a new Pd(II) aerobic alcohol oxidation catalyst system and comparison of all three catalytic systems for general substrate scope, and scope relevant to the synthesis of complex targets.

\section{Results and Discussion}

Recently, we have disclosed a mechanistic study on the aerobic oxidation of alcohols using Pd $(\mathrm{IiPr})(\mathrm{OAc})_{2}\left(\mathrm{H}_{2} \mathrm{O}\right)(\mathbf{1}) .{ }^{33 \mathrm{i}}$ In this study, it was found that using more basic carboxylates as the anionic ligand for Pd resulted in increased rates of oxidation. Applying this finding has led to the development of a third system for the Pdcatalyzed aerobic oxidation of alcohols in which 
acetate has been substituted by pivalate (PivO). The resulting catalytic system uses $1.0 \mathrm{~mol} \%$ of catalyst loading of Pd-(IiPr)(OPiv) 2 (2) along with $0.5 \mathrm{~mol} \%$ of PivOH under an air atmosphere at room temperature to oxidize a variety of alcohols.
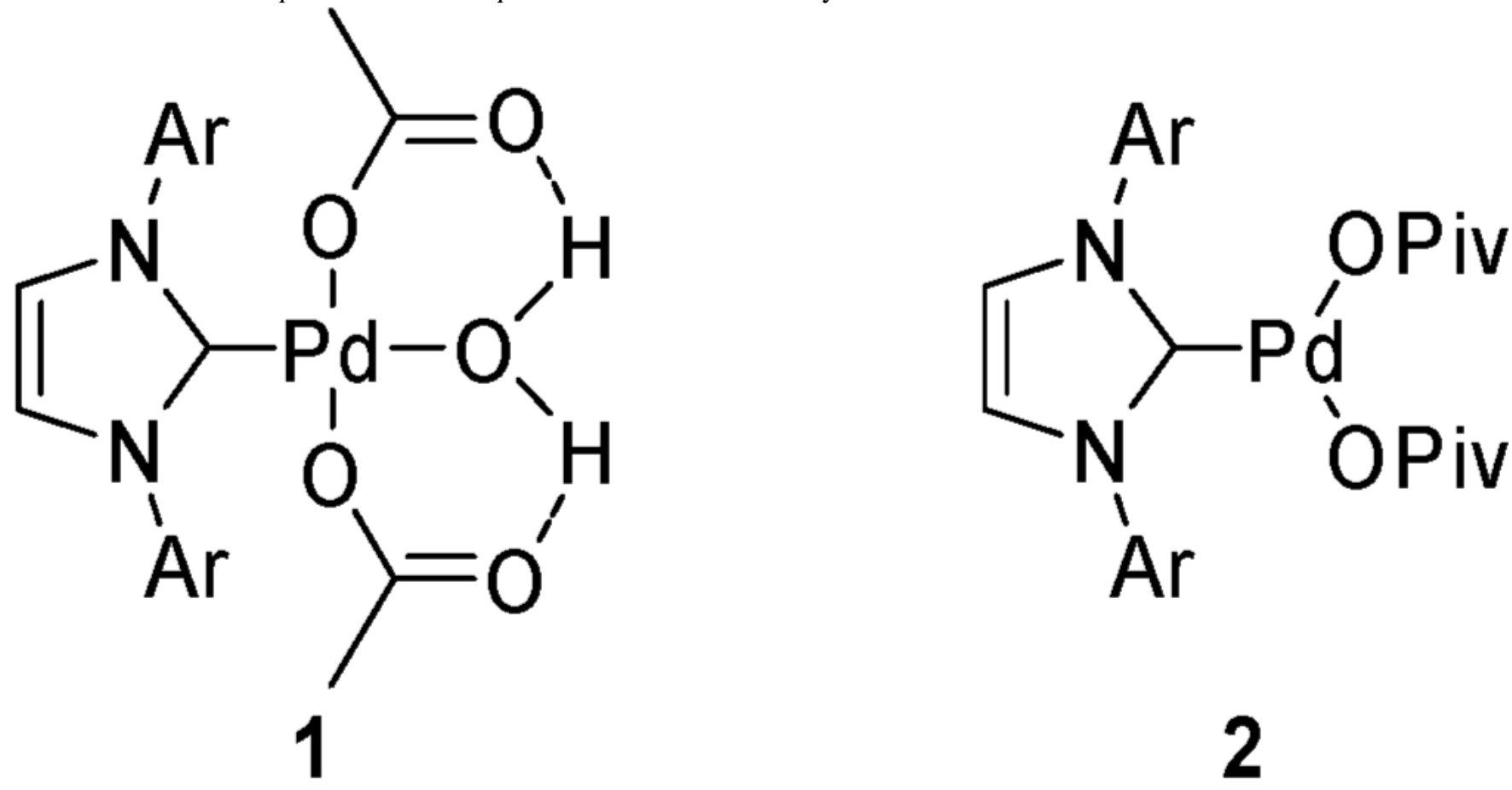

\section{$\operatorname{Ar}=2,6$-di'Pr-Phenyl}

\section{Evaluation of Substrate Scope}

\section{Oxidation of Benzylic Alcohols with $\mathrm{Pd}(\mathrm{OAc})_{2} / \mathrm{TEA}$}

Generally, benzylic alcohols oxidize well using this system (Table 1). Electronics do not seem to play a significant role on isolated yields with both electron-rich and electron-poor benzylic alcohols oxidizing well. A hindered secondary alcohol $3 \mathbf{k}$ also oxidizes under these conditions, albeit with a lower yield and an extended reaction time (entry 22). Of note, $p$-(methylthio) benzyl alcohol 3f oxidizes poorly with Pd-black formation observed (entries 12). A potential limitation is with alcohols that can chelate the Pd(II) catalyst, either as a starting material or product, resulting in observed inhibition of oxidation (entries 28 and 30).

\section{Oxidation of Benzylic Alcohols with 1}

Benzylic alcohols are excellent substrates for this catalyst, with electron-rich alcohols having the fastest rates (Table 1). ${ }^{34}$ Compared with the $\mathrm{Pd}(\mathrm{OAc})_{2} / \mathrm{TEA}$ system, the sterically hindered alcohol 3k oxidizes much more efficiently (entry 23). Also, $p$-(methylthio)benzyl alcohol $\mathbf{3 f}$ oxidizes well under standard conditions, and with a slightly modified procedure provides a $90 \%$ isolated yield of the desired product with no oxidation of the sulfur (entries 13 and 14). Of practical significance, $\mathbf{1}$ can be prepared in situ from commercially available starting materials by using $\mathrm{Pd}(\mathrm{OAc})_{2}$, IiPr- $\mathrm{HBF}_{4}$, and $\mathrm{KO}^{t} \mathrm{Bu}$, to provide an effective oxidation (entry 2). For the oxidation of the electronically activated substrate, $p$-methoxybenzyl alcohol $\mathbf{3 c}$, the catalyst loading can be lowered to $0.1 \mathrm{~mol} \%$ to provide complete conversion representing 
1000 turnovers (entry 8). Once again, this oxidation system is not successful for the oxidation of $\mathbf{3 m}$ and $\mathbf{3 n}$ (entries 29 and 31).

By increasing the concentration of $\mathrm{AcOH}$ to $4 \mathrm{~mol} \%$ on a 1-mmol scale, this oxidation system can be rendered effective for the oxidation of benzylic alcohols under an air atmosphere (entries 3, 7, 21, and 26). This was only the second example of a homogeneous Pd-catalyst effective for the oxidation of alcohols under ambient pressure of air. ${ }^{27} \mathrm{~d}$ By using these modified conditions and increasing the $\mathrm{AcOH}$ additive from $4 \mathrm{~mol} \%$ to $5 \mathrm{~mol} \%$, the oxidation of secphenethyl alcohol 3a can be accomplished on a 1-g scale in 97\% isolated yield (entry 3). The ability to modulate the catalysis by addition of $\mathrm{AcOH}$ allows the use of lower oxygen pressures and potential tuning of this system for a particular substrate.

\section{Oxidation of Benzylic Alcohols with 2}

This system compares well with both $\mathrm{Pd}(\mathrm{OAc})_{2} / \mathrm{TEA}$ and 1 for the oxidation of benzylic alcohols. Once again primary, secondary, and cyclic benzylic alcohols oxidize to completion under very mild conditions (ambient temperature and air filled balloon) while using low catalyst loadings (1 mol \%). However, an electron-deficient benzylic alcohol 3i does not oxidize well (entry 18). This system also works well for the oxidation of $p$-(methylthio)benzyl alcohol 3f, providing $92 \%$ conversion of the alcohol with no Pd-black formation (entry 15). The sterically encumbered benzylic alcohol 3k only oxidizes to $23 \%$ conversion under the standard conditions showing a potential limitation of this system (entry 24).

\section{Oxidation of Aliphatic and Allylic Alcohols with $\mathrm{Pd}(\mathrm{OAc})_{2} / \mathrm{TEA}$}

The oxidation of straight chain and cyclic secondary aliphatic alcohols under standard conditions is successful (Table 2). This includes oxidation of the sterically encumbered alcohol, 2-adamantanol 5c,in a slightly lower yield. A 1,4-diol 5d oxidizes to the corresponding lactone (entry 6). The oxidation also works well for primary aliphatic alcohols; however, the oxidation of straight chain, primary aliphatic alcohols requires modification of the standard conditions by lowering the substrate concentration (vide infra).

As with most Pd-catalyzed alcohol oxidations, allylic alcohols proved to be a more challenging substrate class. Cyclic allylic alcohol $\mathbf{5 j}$ oxidizes well with this system but myrtenol $\mathbf{5 l}$ only oxidizes to $82 \%$ conversion (entries 16 and 22). Straight chain, primary allylic alcohols do not oxidize well with this system even under various modified conditions (entries 19, 25, and 26). The difficulty with oxidation of allylic alcohols is attributed to the ability of $\alpha, \beta$-unsaturated carbonyl compounds to chelate $\operatorname{Pd}(0)$, thus inhibiting oxidation. 35

\section{Oxidation of Aliphatic and Allylic Alcohols with 1}

By decreasing the AcOH concentration from $2 \mathrm{~mol} \%$ to $1 \mathrm{~mol} \%$, straight chain and cyclic aliphatic secondary alcohols oxidize well with $0.5 \mathrm{~mol} \% 1$ (Table 2). As with benzylic alcohols, oxidation of secondary aliphatic alcohols could be performed under an air atmosphere (1 atm) with an increase in AcOH concentration, from 1 to $2 \mathrm{~mol} \%$ (entry 8). Primary aliphatic alcohols proved more challenging. Further optimization led to lowering the molarity of the reaction and switching from $\mathrm{AcOH}$ to $5 \mathrm{~mol} \% \mathrm{ofBu}_{4} \mathrm{NOAc}$ to obtain decanal and octadecanal in moderate yields (entries 12 and 13). In the case of benzylic and secondary aliphatic alcohols, it was found that adding small amounts of $\mathrm{AcOH}$ allowed for more consistent oxidation presumably by slowing the oxidation rate thus preventing catalyst decomposition. However, the use of additive $\mathrm{AcOH}$ in the oxidation of primary aliphatic alcohols resulted in slow oxidation possibly due to the formation of small amounts of overoxidized product, which would result in decreased oxidation rates. Added acid has been shown to slow the rate of oxidation through an inhibitory pathway. ${ }^{33 i}$ Additionally, while elucidating the mechanistic details, we observed a first-order rate dependence on $\left[\mathrm{Bu}_{4} \mathrm{OAc}\right]$ but considerable decomposition of 
catalyst occurs at high levels of this additive. Therefore, in the case of primary aliphatic alcohols, small amounts of $\mathrm{Bu}_{4} \mathrm{NOAc}$ were used to accelerate the oxidation thus resulting in improved yields of aldehyde. Allylic alcohols oxidize better with 1 than with $\mathrm{Pd}(\mathrm{OAc})_{2} / \mathrm{TEA}$. The secondary allylic alcohol $\mathbf{5 i}$ and cyclic allylic alcohol $\mathbf{5} \mathbf{j}$ both oxidize well under standard conditions (entries 14 and 17). Myrtenol $\mathbf{5 l}$ and geraniol $\mathbf{5 k}$ require modified conditions for successful oxidations (entries 20 and 23). Unfortunately, the oxidation product of geraniol shows a 5.4:1 mixture of cis/trans isomers.

\section{Oxidation of Aliphatic and Allylic Alcohols with 2}

Catalyst 2 oxidizes secondary aliphatic alcohols successfully, although the cyclic aliphatic alcohol 5e did not oxidize to complete conversion (Table 2). Unfortunately, it was concluded that this catalyst was not suitable for the oxidation of primary aliphatic alcohols due to very slow conversion. We hypothesize that due to the steric bulk associated with the ligands of this catalyst, one of the pivalates may dissociate from $\mathbf{2}$. This would render $\mathbf{2}$ the most Lewis acidic of the three catalysts explored and thereby more susceptible to product inhibition by good Lewis bases such as aldehydes. Although this catalyst system was unsuccessful for the oxidation of primary aliphatic alcohols, it performed better with allylic alcohols. Both myrtenol $\mathbf{5 l}$ and a cyclic allylic alcohol $\mathbf{5 j}$ oxidize to completion under standard conditions (entries 18 and 24). The secondary allylic alcohol $\mathbf{5 i}$ only oxidizes to $62 \%$ conversion (entry 15 ). Geraniol $\mathbf{5 k}$ oxidizes to $68 \%$ conversion but in contrast to oxidation with $\mathbf{1}$, no double bond isomerization is observed under the milder conditions used for this catalyst system (entry 7).

\section{Functionalized Alcohols}

As observed above, alcohols that have the ability to chelate with metals can be problematic substrates for oxidation. Inhibition of oxidation or decomposition of the catalyst is generally associated with these substrates. Unfortunately, this limits the use of several important substrate classes in Pd-catalyzed aerobic oxidations. Therefore, we were not enthusiastic about evaluating substrates that were more functionalized and related to the synthesis of complex targets. However, evaluation of monoprotected 1,2- and 1,3-diols proved fruitful, and many of these potentially chelating substrates worked well with all three catalysts as described below.

\section{Oxidation of 1,3-Monoprotected Diols}

For secondary alcohol substrates containing a protected primary alcohol, $\mathrm{Pd}(\mathrm{OAc})_{2} / \mathrm{TEA}$ is the most versatile, giving excellent isolated yields of TBS 8a, acetyl $\mathbf{8 b}$, trityl $\mathbf{8 c}$, and benzyl $\mathbf{8 d}$ protected $\beta$-alkoxy-ketones (Table 3, entries 1, 4, 7, and 10). Of particular note, oxidation of 7d proceeds well even on a 30-mmol (5.4 g) scale (entry 10) with no special considerations for the heterogeneous (gas/ liquid) conditions employed. This system also effectively oxidizes the sterically encumbered alcohol $\mathbf{7 e}$ in a $90 \%$ isolated yield (entry 13).

Using 1 proved to be a good catalyst for the oxidation of secondary alcohols containing a protected primary alcohol, yielding slightly lower conversions than the TEA system for TBS, trityl, and benzyl protected diols (Table 3, entries 2, 5, 8, and 11). Catalyst 2 did not oxidize secondary alcohols containing a protected primary alcohol as efficiently as the other catalysts. TBS and benzyl protected diols oxidize to moderate conversions while the acetyl and trityl protected alcohols are poorer substrates (entries 3, 6, 9, and 12). For a primary alcohol containing a protected secondary alcohol $\mathbf{7 f}$, both $\mathrm{Pd}(\mathrm{OAc})_{2} / \mathrm{TEA}$ and $\mathbf{1}$ oxidize the trityl protected alcohol in $>90 \%$ conversion (entries 16 and 17). However, a primary alcohol with a benzyl protected secondary alcohol $\mathbf{7} \mathbf{g}$ was not as successful, presumably due to chelation (entries 18 and 19). Catalyst 2 does not oxidize primary, nonbenzylic alcohols. It is important to note, changing the nature of the protecting group has little impact on the ability to oxidize the substrate especially when using $\mathrm{Pd}(\mathrm{OAc})_{2} / \mathrm{TEA}$. 


\section{Oxidation of 1,2-Monoprotected Diols}

For secondary alcohols containing a TBS 9a or trityl 9c protected alcohol, good yields of the desired ketones are achieved by using the $\mathrm{Pd}(\mathrm{OAc})_{2}$ /TEA oxidation system (Table 4 , entries 1 and 7). In contrast, secondary alcohol $\mathbf{9 b}$, with an acetyl protecting group, does surprisingly poorly with the $\mathrm{Pd}(\mathrm{OAc})_{2} / \mathrm{TEA}$ but 1 promotes complete conversion and a $99 \%$ isolated yield (entry 4). Catalyst 2 did not oxidize these alcohols with comparable efficiency to Pd-(OAc) $)_{2} /$ TEA or $\mathbf{1}$. For oxidation of the enantiomerically enriched substrate $\mathbf{9 d}$, containing a primary alcohol and a trityl protected secondary alcohol, $\mathrm{Pd}(\mathrm{OAc})_{2} /$ TEA and 1 both perform equally well with an $85 \%$ yield of the aldehyde when using $\mathrm{Pd}(\mathrm{OAc})_{2} / \mathrm{TEA}$ (entries 10 and 11 ). In addition, the product was obtained with no racemization. Overall, 1,2-monoprotected diols are viable substrates for Pd-catalyzed aerobic oxidative protocols.

\section{Protected 1,2-Amino Alcohols}

While unprotected amino alcohols will not oxidize with these catalyst systems, protecting the amine may allow for facile alcohol oxidation. To test this, norephedrine was Boc protected and submitted to the oxidation conditions (Table 4, entries 12-14). As with most functionalized alcohols, $\mathrm{Pd}-(\mathrm{OAc})_{2} / \mathrm{TEA}$ outperformed the other catalysts providing a $97 \%$ yield of the desired R-amino-ketone. No racemization of $\mathbf{1 0 e}$ is observed with the two methods at room temperature but a slight erosion of enantiomeric excess ( $99 \%$ to $97 \%$ ee) is observed with catalyst 1 at $60{ }^{\circ} \mathrm{C}$. A more difficult substrate, $N$-boc-valinol 11, was tested with the Pd $(\mathrm{OAc})_{2} /$ TEA catalyst system where the aldehyde is obtained in modest conversion with no loss of stereo-chemical integrity. However, a major byproduct 13, the ester formed from two molecules of $\mathrm{N}$-boc-valinol, was observed (Table 5). This observation was not entirely surprising considering primary aliphatic alcohols required modified reaction conditions for effective oxidation. However, while ester formation was observed for other primary aliphatic alcohols, the relative ratios of aldehyde to ester were much less significant (>20:1). In the case of $N$-boc-valinol, substantially more ester is formed under these conditions (Table 5, entry 1). We reasoned the undesired enhancement of ester formation is attributed to the ability of the resulting aldehyde to chelate to the Pd catalyst. Lewis acid activation allows for nucleophilic attack of an alcohol on the aldehyde to result in a new Pd-alkoxide derived from the hemiacetal. Subsequent $\beta$-hydride elimination leads to ester formation. Presumably, this mechanism is responsible for lactone formation from a $\gamma$-diol via an intramolecular path (Table 2, entry 6). In the current study, ester formation is not a desirable product but the design of a system that converts alcohols directly to the acid oxidation state is currently under study. 36

To test if chelation is the most likely contributor to the increased ester formation, we evaluated several modified reaction conditions. It was found that ester formation can be limited by increasing the concentration of competing ligands in the reaction by raising the THF and/or TEA concentration (Table 5, entries 4-10). Additionally, lowering the entropic barrier by decreasing the molarity of the substrate leads to modest improvements (Table 5, entries 1-3). While improvements in the ratio of alde-hyde to ester are observed, a corresponding slowing of the oxidation rate also results, leading to a more selective but inefficient oxidation. The use of $\mathbf{1}$ for the oxidation of $\mathrm{N}$-boc-valinol was also ineffective and leads to complete racemization of the aldehyde product. This $N$-boc protected R-amino primary alcohol is a difficult substrate for these Pd-catalyzed alcohol oxidations.

\section{Chemoselective Alcohol Oxidations}

Chemoselectivity in alcohol oxidations avoids the use of protecting groups and streamlines the chemical synthesis process. There are very few examples of highly chemoselective catalysts for alcohol oxidations. ${ }^{37}$ Chemoselectivity, between a primary and a secondary alcohol, was tested by submitting 1,6-heptanediol 14 to oxidation with all three catalyst systems (Table 6). Conditions developed to oxidize secondary alcohols for the $\mathrm{Pd}(\mathrm{OAc})_{2} / \mathrm{TEA}$ system lead to a 
chemoselective oxidation of the secondary alcohol to yield a nearly 6 to 1 ratio of $\mathbf{1 5}$ to $\mathbf{1 6}$ (entry 1). Significant oxidation to $\mathbf{1 7}$ is also observed making this a less practical method for chemoselective oxidation. In contrast, using conditions developed to oxidize primary alcohols yields almost equal amounts of $\mathbf{1 5}, \mathbf{1 6}$, and $\mathbf{1 7}$ (entry 2). In comparison, using conditions developed for oxidation of primary aliphatic alcohols with catalyst $\mathbf{1}$, no chemoselectivity for the initial oxidation to $\mathbf{1 5}$ and $\mathbf{1 6}$ is observed but the oxidation to $\mathbf{1 7}$ is slower (entry 3). Testing of other conditions with catalysts $\mathbf{1}$ and $\mathbf{2}$ was severely limited by the solubility of the substrate in toluene.

\section{Diastereoselective Oxidations of Substituted Cy clohexanols}

When oxidizing 4-methylcyclohexanol with catalyst $\mathbf{1}$, the cis isomer oxidized rapidly while the trans isomer oxidized considerably slower. An initial hypothesis was the alcohol must assume the axial position to undergo $\beta$-hydride elimination. A cis/trans mixture of 4-tertbutylcyclohexanol 18 was chosen as a model substrate to test this hypothesis. The cis diastereomer of the mixture, which is locked in the axial position, was expected to oxidize faster than the trans diastereomer. However, submitting the isomeric mixture of $\mathbf{1 8}$ to standard conditions for catalyst 1 gave no oxidation. In contrast, $\mathrm{Pd}(\mathrm{OAc})_{2} / \mathrm{TEA}$ oxidizes 18 effectively but no diastereoselectivity is observed (eq 1).

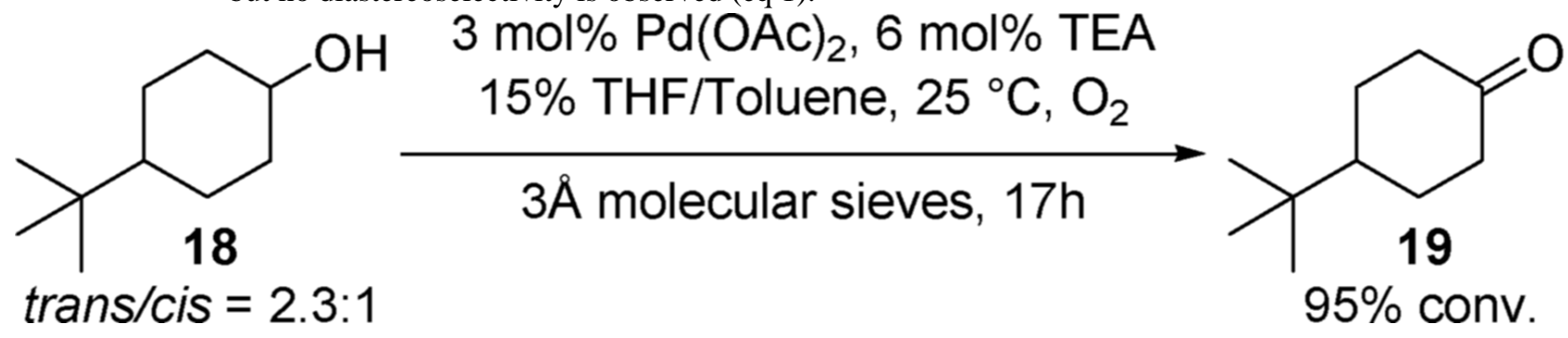

Considering substrate $\mathbf{1 8}$ does not oxidize with catalyst $\mathbf{1}$, we chose to explore the original hypothesis by oxidizing cis/trans mixtures of the three constitutional isomers of methyl cyclohexanol (Table 7). Using $\mathrm{Pd}(\mathrm{OAc})_{2} / \mathrm{TEA}$, complete oxidation of the mixture of diastereomers results and no diastereoselectivity is observed even at low conversions. In contrast, catalyst 1 promotes a highly diastereoselective oxidation of each alcohol. For 2- and 4-methylcyclohexanol, the cis isomer oxidizes faster whereas the trans isomer of 3methylcyclohexanol oxidizes faster. The isomers corresponding to the fast reacting diastereomers contain a substituent in an axial position. Out of the three constitutional isomers, cis/ trans-2-methylcyclohexanol results in the best resolutions. Using catalyst 1 a 65 to 1 ratio (selectivity factor $=11$ ) of trans to cis diastereomers at $48 \%$ conversion is observed (entry 2 ). Catalyst $\mathbf{2}$ oxidizes all three alcohols in higher diastereoselectivity than catalyst $\mathbf{1}$ with $\mathbf{2 0}$ giving an excellent resolution of 575 to 1 ratio (selectivity factor $=23$ ) of trans to cis diastereomers at $45 \%$ conversion (entry 3 ).

Interactions between the ligand, carboxylate, and substrate play a role in diastereoselectivity of the oxidation. As the substitution on the cyclohexane ring becomes closer to the site of oxidation, higher selectivity factors are observed. The size difference between the carboxylates on $\mathbf{1}$ and $\mathbf{2}$ leads to an enhancement of the selectivity factor as well. Even with these trends, it is difficult to propose a model when a change in rate-limiting step from $\beta$-hydride elimination to deprotonation for the different isomers is possible. Considering the implications to asymmetric catalysis, investigation of these possibilities will be a subject of future research. 


\section{Conclusions}

The current systems compare favorably to the benchmarks established by Uemura and Sheldon. Chief among the advantages are the mild conditions employed and higher catalytic activity for 1 and $\mathbf{2}$. The mild nature of the reaction conditions presented herein allows oxidation of functionalized substrates with protecting groups which would likely not withstand the forcing conditions in other Pd-catalyzed aerobic alcohol oxidations.

Of the three catalysts, catalyst 2 uses the mildest reaction conditions (room temperature, $1 \mathrm{~mol}$ $\%$ of catalyst, and air as the $\mathrm{O}_{2}$ source) but the substrate scope of this catalyst is the most limited. In comparison, catalyst $\mathbf{1}$ and $\mathrm{Pd}(\mathrm{OAc})_{2} / \mathrm{TEA}$ both prove quite effective for a broad scope of substrates. The advantages of catalyst 1 are (1) low catalyst loadings for a Pd-catalyzed alcohol oxidation ( 0.1 to $1.0 \mathrm{~mol} \%)$, (2) replacement of $\mathrm{O}_{2}$ with ambient air by raising [AcOH] ( 2 to $5 \mathrm{~mol} \%$ ), (3) a diastereoselective oxidation of substituted cyclohexanols, and (4) effective oxidation of allylic alcohols. The advantages of the $\mathrm{Pd}(\mathrm{OAc})_{2} /$ TEA system are (1) simplicity of the reaction procedure, (2) the use of ambient temperature, (3) lack of racemization of nonracemic substrates, (4) moderately chemoselective oxidations, (5) easy scalability (30 $\mathrm{mmol}$ ), and (6) generally excellent yields for functionalized alcohols. The main limitations of these systems are (1) the use of basic groups inhibit the oxidation and (2) substrate solubility in the reaction solvent. Even though catalysts $\mathbf{1}$ and $\mathbf{2}$ are more efficient in terms of catalyst loading and oxygen concentration, $\mathrm{Pd}(\mathrm{OAc})_{2} / \mathrm{TEA}$ is the easiest system for evaluating a new substrate due to readily available reagents and good substrate scope. However, catalyst $\mathbf{1}$ has the greatest ability to be modulated through changing temperature, the oxygen concentration, and amounts of additive $\mathrm{AcOH}$ or $\mathrm{Bu}_{4} \mathrm{NOAc}$. Overall, these systems showed diverse scope and excellent reactivity under mild conditions.

The major challenge in developing efficient catalysts for Pd-catalyzed aerobic alcohol oxidations has been the identification of effective and stable ligands, especially considering that phosphine ligands are susceptible to oxidation under aerobic conditions. However, the current study showcases that the careful selection of ligand/base leads to excellent results in Pd-catalyzed aerobic oxidations. Using the knowledge that excess tertiary amine is necessary for effective oxidations and leads to inhibition of oxidation rates, we designed a catalyst that uses a single $\mathrm{NHC}$ ligand on $\mathrm{Pd}(\mathrm{OAc})_{2}$. This allowed for significantly lower catalyst loadings. In addition, the catalytic activity of $\mathbf{1}$ was improved by changing the nature of the carboxylate anionic ligand from acetate to pivalate. Not only can the carboxylate be tuned, it is also possible to modify the NHC ligands electronically and structurally for development of desired reactivity. Considering this, future work in our laboratory is focused on the discovery of new Pd(II)-catalyzed oxidation reactions with applications in asymmetric catalysis with related ligands and catalyst design approaches.

\section{Experimental Section}

\section{General Considerations}

The alcohols used as substrates, $\mathrm{HOAc}$, and $\mathrm{Bu}_{4} \mathrm{NOAc}$ were purchased and used as received. $\left[\mathrm{Pd}(\mathrm{IiPr}) \mathrm{Cl}_{2}\right]_{2} 28 \mathrm{f}$ and $\mathbf{1}^{34}$ were prepared according to literature methods. $\mathrm{PhCH}_{3}$ used as solvent was dried before use by passing through a column of activated alumina. THF was dried by distilling from sodium benzophenone ketyl. TEA is purified via distillation from $\mathrm{CaH}_{2}$. The $3 \AA$ molecular sieves were powdered and activated by placing them under vacuum in a flask and heating with a Bunsen burner for ca. 2 min. GC conversions for reactions with <99\% conversion were determined relative to undecane or tetradecane as internal standard. 


\section{Preparation of $\mathrm{Pd}(\mathrm{liPr})(\mathrm{OPiv})_{2}$ (2)}

To a 20 -mL scintillation vial was added $30 \mathrm{mg}$ of $\left[\mathrm{Pd}(\operatorname{IiPr}) \mathrm{Cl}_{2}\right]_{2}(0.027 \mathrm{mmol}, 1.0$ equiv) and $22.7 \mathrm{mg}$ of AgOPiv ( $0.108 \mathrm{mmol}, 4.025$ equiv). In the dark (wrapped in aluminum foil), $6 \mathrm{~mL}$ of cooled $\mathrm{CH}_{2} \mathrm{Cl}_{2}\left({ }^{\circ} \mathrm{C}\right)$ was added and the mixture was allowed to slowly warm to room temperature. After $12 \mathrm{~h}$, the reaction mixture was concentrated to ca. $2 \mathrm{~mL}$ and placed in a 2$\mathrm{mL}$ microcentrifuge tube. The tube was placed in a centrifuge and spun for ca. $3 \mathrm{~min}$. The yellow solution was transferred into a $10-\mathrm{mL}$ flask and the solvent removed in vacuo to yield $35 \mathrm{mg}$ of a yellow solid (96\% yield). $\mathrm{Mp}>161^{\circ} \mathrm{C}$ dec; $\mathrm{IR}(\mathrm{KBr}) 2967,2928,2868,1628,1559$, $1477,1465,1415,1363,1207 \mathrm{~cm}^{-1} ;{ }^{1} \mathrm{H}$ NMR $\left(\mathrm{CD}_{2}-\mathrm{Cl}_{2}\right) \delta 0.91(\mathrm{~s}, 18 \mathrm{H}), 1.1(\mathrm{~d}, J=7.25 \mathrm{~Hz}$, $12 \mathrm{H}), 1.4(\mathrm{~d}, J=6.87 \mathrm{~Hz}, 12 \mathrm{H}), 2.70$ (apparent sept., $J=6.78 \mathrm{~Hz}, 4 \mathrm{H}), 7.17(\mathrm{~s}, 2 \mathrm{H}), 7.40-7.49$ (m, 4H), 7.55-7.65 (m, 2H); ${ }^{13} \mathrm{C}$ NMR $\left(\mathrm{CD}_{2} \mathrm{Cl}_{2}\right) \delta 23.0,25.7,27.1,28.5,39.5,124.3,126.2$, 130.5, 135.0, 146.3, 148.7, 192.5. Elemental Anal. Calcd: C 63.74, H 7.81, N 4.02. Found: C 63.76, H 7.72, N 3.91 .

\section{$\mathrm{Pd}(\mathrm{OAc})_{2} / \mathrm{TEA}-$ Catalyzed Oxidation of Benzylic, Secondary Aliphatic, and Cylic Allylic Alcohols}

To a $25-\mathrm{mL}$ round-bottom flask equipped with a stir bar was added $6.7 \mathrm{mg}$ of $\mathrm{Pd}(\mathrm{OAc})_{2}(0.03$ mmol, 0.03 equiv) and $200 \mathrm{mg}$ of powdered, freshly activated $3 \AA$ molecular sieves. To this was added $0.5 \mathrm{~mL}$ of THF, $2.83 \mathrm{~mL}$ of toluene, and $8.4 \mu \mathrm{L}$ of TEA ( $0.06 \mathrm{mmol}, 0.06$ equiv). A balloon of oxygen was attached via a three-way joint. The flask was evacuated and refilled with oxygen three times followed by vigorous stirring for $30 \mathrm{~min}$ at room temperature under $\mathrm{O}_{2}$. To this solution was added $1 \mathrm{mmol}$ of alcohol and the mixture was stirred vigorously at room temperature under a balloon of $\mathrm{O}_{2}$. The reaction progress was monitored by GC. After $12 \mathrm{~h}$, the reaction mixture was placed directly on a plug of silica, washed with pentane to remove toluene, and eluted with diethyl ether. The ether was removed in vacuo to yield the desired carbonyl product. For alcohols with incomplete oxidation, the desired carbonyl product was isolated via column chromatography with mixtures of diethyl ether/hexanes as the eluting solvent. Purity was confirmed by NMR.

\section{$\mathrm{Pd}(\mathrm{OAc})_{2}$ /TEA-Catalyzed Oxidation of Primary Aliphatic Alcohols}

To a 50-mL round-bottom flask equipped with a stir bar was added $6.7 \mathrm{mg}$ of $\mathrm{Pd}(\mathrm{OAc})_{2}(0.03$ mmol, 0.03 equiv) and $250 \mathrm{mg}$ of powdered, freshly activated $3 \AA$ molecular sieves. To this was added $2.6 \mathrm{~mL}$ of THF, $9.4 \mathrm{~mL}$ of toluene, $1.0 \mathrm{~mL}$ of $0.01 \mathrm{M} \mathrm{Bu}_{4} \mathrm{NOAc} /$ toluene $(0.01$ mmol, 0.01 equiv), and $25 \mu \mathrm{L}$ of TEA ( $0.18 \mathrm{mmol}, 0.18$ equiv). A balloon of oxygen was attached via a three-way joint. The flask was evacuated and refilled with oxygen three times followed by vigorous stirring for $30 \mathrm{~min}$ at room temperature under $\mathrm{O}_{2}$. To this solution was added $1 \mathrm{mmol}$ of alcohol and the mixture was stirred vigorously at room temperature under a balloon of $\mathrm{O}_{2}$. The reaction progress was monitored by GC. After $12 \mathrm{~h}$, the reaction mixture was placed directly on a plug of silica, washed with pentane to remove toluene, and eluted with diethyl ether. The ether was removed in vacuo to yield the desired carbonyl product. For alcohols with incomplete oxidation, the desired carbonyl product was isolated via column chromatography with diethyl ether/hexanes as the eluting solvent. Purity was confirmed by NMR.

\section{$\mathrm{Pd}(\mathrm{liPr})(\mathrm{OAc})_{\mathbf{2}}\left(\mathrm{H}_{\mathbf{2}} \mathrm{O}\right)$-Catalyzed Oxidation of Benzylic and Secondary Allylic Alcohols}

To a 10-mL round-bottom flask equipped with a stir bar was added $3.2 \mathrm{mg}$ of $\mathrm{Pd}(\mathrm{IiPr})$ $(\mathrm{OAc})_{2}\left(\mathrm{H}_{2} \mathrm{O}\right)(0.005 \mathrm{mmol}, 0.005$ equiv) and $150 \mathrm{mg}$ of powdered, freshly activated $3 \AA$ molecular sieves. To this was added $1.6 \mathrm{~mL}$ of toluene and $0.4 \mathrm{~mL}$ of $0.1 \mathrm{M} \mathrm{AcOH} /$ toluene ( $0.02 \mathrm{mmol}, 0.02$ equiv) followed by $1 \mathrm{mmol}$ of alcohol. A reflux condenser was attached to the flask and a balloon of oxygen was attached to the top of the condenser via a three-way joint. The flask was evacuated and refilled with oxygen three times followed by vigorous stirring 
for ca. $10 \mathrm{~min}$. The apparatus was placed in a $60^{\circ} \mathrm{C}$ oil bath. The reaction progress was monitored by GC. After completion, the reaction mixture was cooled to ambient temperature and placed directly on a plug of silica, washed with pentane to remove toluene, and eluted with diethyl ether. The diethyl ether was removed in vacuo to yield the desired carbonyl product. For alcohols with incomplete oxidation, the desired carbonyl product was isolated via column chromatography with mixtures of diethyl ether/hexanes as the eluting solvent. Purity was confirmed by NMR.

\section{$\mathrm{Pd}(\mathrm{IiPr})(\mathrm{OAc})_{\mathbf{2}}\left(\mathrm{H}_{\mathbf{2}} \mathrm{O}\right)$-Catalyzed Oxidation of Secondary Aliphatic Alcohols}

To a $10 \mathrm{~mL}$ round-bottom flask equipped with a stir bar was added $3.2 \mathrm{mg}$ of $\mathbf{1}(0.005 \mathrm{mmol}$, 0.005 equiv) and $150 \mathrm{mg}$ of powdered, freshly activated $3 \AA$ molecular sieves. To this was added $1.8 \mathrm{~mL}$ of toluene and $0.2 \mathrm{~mL}$ of $0.1 \mathrm{M} \mathrm{AcOH} /$ toluene $(0.01 \mathrm{mmol}, 0.01$ equiv) followed by $1 \mathrm{mmol}$ of alcohol. A reflux condenser was attached to the flask and a balloon of oxygen was attached to the top of the condenser via a three-way joint. The flask was evacuated and refilled with oxygen three times followed by vigorous stirring for ca. $10 \mathrm{~min}$. The apparatus was placed in a $60^{\circ} \mathrm{C}$ oil bath. The reaction progress was monitored by GC. After completion, the reaction mixture was cooled to ambient temperature and placed directly on a plug of silica, washed with pentane to remove toluene, and eluted with diethyl ether. The diethyl ether was removed in vacuo to yield the desired carbonyl product. For alcohols with incomplete oxidation, the desired carbonyl product was isolated via column chromatography with mixtures of diethyl ether/hexanes as the eluting solvent. Purity was confirmed by NMR.

\section{$\mathrm{Pd}(\mathrm{liPr})(\mathrm{OAc})_{\mathbf{2}}\left(\mathrm{H}_{\mathbf{2}} \mathrm{O}\right)$-Catalyzed Oxidation of Primary Aliphatic and Allylic Alcohols}

To a 50-mL round-bottom flask equipped with a stir bar was added $4.7 \mathrm{mg}$ of $\mathrm{Pd}(\mathrm{IiPr})$ $(\mathrm{OAc})_{2}\left(\mathrm{H}_{2} \mathrm{O}\right)\left(0.0075 \mathrm{mmol}, 0.0075\right.$ equiv), $15.1 \mathrm{mg}$ of $\mathrm{Bu}_{4} \mathrm{NOAc}(0.05 \mathrm{mmol}, 0.05$ equiv), and $200 \mathrm{mg}$ of powdered, freshly activated $3 \AA$ molecular sieves. To this was adde $10.0 \mathrm{~mL}$ of toluene followed by $1 \mathrm{mmol}$ of alcohol. A reflux condenser was attached to the flask and a balloon of oxygen was attached to the top of the condenser via a three-way joint. The flask was evacuated and refilled with oxygen three times followed by vigorous stirring for ca. $10 \mathrm{~min}$. The apparatus was placed in a $60{ }^{\circ} \mathrm{C}$ oil bath. The reaction progress was monitored by GC. After completion, the reaction mixture was cooled to ambient temperature and placed directly on a plug of silica, washed with pentane to remove toluene, and eluted with diethyl ether. The diethyl ether was removed in vacuo to yield the desired carbonyl product. For alcohols with incomplete oxidation, the desired carbonyl product was isolated via column chromatography with mixtures of diethyl ether/hexanes as the eluting solvent. Purity was confirmed by NMR.

\section{Pd(liPr)(OPiv) 2 -Catalyzed Oxidation of Benzylic, Allylic, and Secondary Aliphatic Alcohols}

To a 25-mL round-bottom flask equipped with a stir bar was added $7.2 \mathrm{mg}$ of $\mathrm{Pd}(\mathrm{IiPr})$ $(\mathrm{OPiv})_{2}(0.01 \mathrm{mmol}, 0.01$ equiv) and $250 \mathrm{mg}$ of powdered, freshly activated $3 \AA$ molecular sieves. To this was added $2.45 \mathrm{~mL}$ of toluene and $0.05 \mathrm{~mL}$ of $0.1 \mathrm{M} \mathrm{PivOH} /$ toluene $(0.005$ mmol, 0.005 equiv). A balloon of air was attached via a three-way joint and the mixture was allowed to stir for $5 \mathrm{~min}$. To the mixture was added $1 \mathrm{mmol}$ of alcohol and the reaction mixture was stirred vigorously. The reaction progress was monitored by GC. After completion, the reaction mixture was cooled to ambient temperature and placed directly on a plug of silica, washed with pentane to remove toluene, and eluted with diethyl ether. The diethyl ether was removed in vacuo to yield the desired carbonyl product. For alcohols with incomplete oxidation, the desired carbonyl product was isolated via column chromatography with mixtures of diethyl ether/hexanes as the eluting solvent. Purity was confirmed by NMR. 


\section{Acknowledgment}

This work was supported by the National Institutes of Health (NIGMS \#RO1 GM63540), Pfizer GRD, and the Dreyfus Foundation (Teacher-Scholar Award). D.R.J. thanks the University of Utah and the ACS Organic Division Fellowship sponsored by the Schering Plough Research Institute for graduate research fellowships. S.S.H. thanks Pfizer GRD for a summer research fellowship. We thank Johnson Matthey for supplies of various palladium salts. We thank Professor Ilya Zharov for designing the cover artwork.

\section{References}

1. Collins JC, Hess WW, Frank FJ. Tetrahedron Lett 1968:3363-3363.

2. Dess DB, Martin JC. J. Org. Chem 1983;48:4155-4156.

3. Harding KE, May LM, Dick KF. J. Org. Chem 1975;40:1664-1665.

4. Pfitzner KE, Moffatt JG. J. Am. Chem. Soc 1965;87:5661-5670.

5. Parikh JR, Doering WE. J. Am. Chem. Soc 1967;89:5505-5507.

6. Corey EJ, Suggs JW. Tetrahedron Lett 1975:2647-2650.

7. Corey EJ, Schmidt G. Tetrahedron Lett 1979:399-402.

8. Mancuso AJ, Swern D. Synthesis 1981:165-185.

9. For an excellent review on the TPAP/NMO oxidation, see: Ley SV, Norman J, Griffith WP, Marsden SP. Synthesis 1994:639-666.666

10. Molecular oxygen has been shown to work as a reoxidant for TPAP but with limited success. For examples, see: aLenz R, Ley SV. J. Chem. Soc., Perkin Trans. 1 1997:3291-3292.3292bMarkó IE, Giles PR, Tsukazaki M, Chellé-Regnaut I, Urch CJ, Brown SM. J. Am. Chem. Soc 1997;119:1266112662.12662cColeman KS, Lorber CY, Osborn JA. Eur. J. Inorg. Chem 1998:1673-1675.1675

11. Ruiz R, Aukauloo A, Journaux Y, Fernández I, Pedro JR, Roselló AL, Cervera B, Castro I, Muñoz MC. Chem. Commun 1998:989-990.

12. Martin SE, Suárez D. Tetrahedron Lett 2002;43:4475-4479.

13. For examples, see:aTang R, Diamond SE, Neary N, Mares F. J. Chem. Soc., Chem. Commun 1978:562.bMatsumoto M, Ito S. Synth. Commun 1984;14:697-700.700cMarkó IE, Giles PR, Tsukazaki M, Chelle'-Regnaut I, Urch CJ, Brown SM. J. Am. Chem. Soc 1997;119:1266112662.12662dHanyu A, Takezawa E, Sakaguchi S, Ishii Y. Tetrahedron Lett 1998;39:55575560.5560eMatsushita T, Ebitani K, Kaneda K. Chem. Commun 1999:265-266.266fDijksman A, Arends IWCE, Sheldon RA. Chem. Commun 1999:1591-1592.1592gMasutani K, Uchida T, Irie R, Katsuki T. Tetrahedron Lett 2000;41:4119-4123.4123hLee M, Chang S. Tetrahedron Lett 2000;41:7507-7510.7510iYamaguchi K, Mori K, Mizugaki T, Ebitani K, Kaneda K. J. Am. Chem. Soc 2000;122:7144-7145.7145jDijksman A, Marino-González A, Mairata I, Payeras A, Arends IWCE, Sheldon RA. J. Am. Chem. Soc 2001;123:6826-6833.6833 [PubMed: 11448187]kMiyata A, Murakami M, Irie R, Katsuki T. Tetrahedron Lett 2001;42:7067-7070.70701Csjernyik G, Éll AH, Fadini L, Pugin B, Bäckvall J-E. J. Org. Chem 2002;67:1657-1662.1662 [PubMed: 11871899] mWolfson A, Wuyts S, De Vos DE, Vankelecom IFJ, Jacobs PA. Tetrahedron Lett 2002;43:81078110.8110

14. For examples, see:aYamada T, Mukaiyama T. Chem. Lett 1989:519-522.522bIwahama T, Sakaguchi S, Nishiyama Y, Ishii Y. Tetrahedron Lett 1995;36:6923-6926.6926cIwahama T, Yosino Y, Keitoku T, Sakaguchi S, Ishii Y. J. Org. Chem 2000;65:6502-6507.6507 [PubMed: 11052094]dSharma VB, Jain SL, Sain B. Tetrahedron Lett 2004;44:383-386.386

15. For examples, see:aMunakata M, Nishibayashi S, Sakamoto H. J. Chem. Soc., Chem. Commun 1980:219-220.220bSemmelhack MF, Schmid CR, Cortés DA, Chou CS. J. Am. Chem. Soc 1984;106:3374-3376.3376cMarkó IE, Giles PR, Tsukazaki M, Brown SM, Urch CJ. Science 1996;274:2044-2045.2045 [PubMed: 8953027]dMarkó IE, Gautier A, Chelle'-Regnaut I, Giles PR, Tsukazaki M, Urch CJ, Brown SM. J. Org. Chem 1998;63:7576-7577.7577eMarkó IE, Giles PR, Tsukazaki M, Chellé-Regnaut I, Gautier A, Brown SM, Urch CJ. J. Org. Chem 1999;64:24332439.2439fMarkó IE, Gautier A, Mutonkole J-L, Dumeunier R, Ates A, Urch CJ, Brown SM. J. Organomet. Chem 2001;624:344-347.347gRagagnin G, Betzemeier B, Quici S, Knochel P. Tetrahedron 2002;58:3985-3991.3991hAnsari IA, Gree R. Org. Lett 2002;4:1507-1509.1509 [PubMed: 11975615]iGamez P, Arends IWCE, Reedijk J, Sheldon RA. Chem. Commun 2003:2414- 
2415.2415jGamez P, Arends IWCE, Sheldon RA, Reedijk J. Adv. Synth. Catal 2004;346:805811.811kMarkó IE, Gautier A, Dumeunier R, Kanae D, Philippart F, Brown SM, Urch CJ. Angew. Chem., Int. Ed 2004;43:1588-1591.1591

16. For examples, see:aHeyns K, Blazejewicz L. Tetrahedron 1960;9:67-75.75bJia C-G, Jing F-Y, Hu W-D, Huang M-Y, Jiang Y-Y. J. Mol. Catal 1994;91:139-147.147

17. Chaudhuri P, Hess M, Müller J, Hildenbrand K, Bill E, Weyhermüller T, Wieghardt K. J. Am. Chem. Soc 1999;121:9599-9610.

18. Martin J, Martin C, Faraj M, Brégeault J-M. Nouv. J. Chim 1984;8:141-143.

19. a Kirihara M, Ochiai Y, Takizawa S, Takahata H, Nemoto H. Chem. Commun 1999:1387-1388. b Maeda Y, Kakiuchi N, Matsumura S, Nishimura T, Kawamura T, Uemura S. J. Org. Chem 2002;67:6718-6724. [PubMed: 12227802] c Reddy SR, Das S, Punniyamurthy T. Tetrahedron Lett 2004;45:3561-3564. d Figiel PJ, Sobczak JM, Ziólkowski JJ. Chem. Commun 2004:244-245. e Velusamy S, Punniyamurthy T. Org. Lett 2004;6:217-219. [PubMed: 14723532]

20. a Hatanaka Y, Imamoto T, Yokoyama M. Tetrahedron Lett 1983;24:2399-2400. b Kim SS, Jung HC. Synthesis 2003:2135-2137.

21. Choudary BM, Kantam ML, Rahman A, Reddy CV, Rao KK. Angew. Chem., Int. Ed 2001;40:763766.

22. For recent reviews with excellent references, see:aMuzart J. Tetrahedron 2003;59:57895816.5816bSheldon RA, Arends IWCE, ten Brink G-J, Dijksman A. Acc. Chem. Res 2002;35:774781.781 [PubMed: 12234207]cSheldon RA, Arends IWCE, Dijksman A. Catal. Today 2000;57:157166.166

23. For examples of heterogeneous Pd-catalyzed aerobic oxidation of alcohols, see: Mori K, Hara T, Mizugaki T, Ebitani K, Kaneda K. J. Am. Chem. Soc 2004;126:10657-10666.10666 [PubMed: 15327324]

24. For examples, see:aZhang N, Mann CM, Shapley PA. J. Am. Chem. Soc 1988;110:65916592.6592bMurahashi S-I, Naota T, Hirai N. J. Org. Chem 1993;58:7318-7319.7319cShapley PA, Zhang N, Allen JL, Pool DH, Liang H-C. J. Am. Chem. Soc 2000;122:1079-1091.1091dCecchetto A, Fontana F, Minisci F, Recupero F. Tetrahedron Lett 2001;42:6651-6653.6653eMuldoon J, Brown SN. Org. Lett 2002;4:1043-1045.1045 [PubMed: 11893217]fMusawir M, Davey PN, Kelly G, Kozhevnikov IV. Chem. Commun 2003:1414-1415.1415

25. a Stahl SS. Angew. Chem., Int. Ed 2004;43:3400-3420. b Stoltz BM. Chem. Lett 2004;33:362-367. c Sigman MS, Jensen DR, Rajaram S. Curr. Opin. Drug Discovery Dev 2002;5:860-869.

26. Nikiforova AV, Moiseev II, Syrkin YK. Zh. Obshch. Khim 1964;33:3239-3242.

27. For examples of Pd-catalyzed aerobic oxidation of alcohols, see:aLloyd WG. J. Org. Chem 1967;32:2816-2819.2819bBlackburn TF, Schwartz J. J. Chem. Soc., Chem. Commun 1977:157158.158cPeterson KP, Larock RC. J. Org. Chem 1998;63:3185-3189.3189dHallman K, Moberg C. Adv. Synth. Catal 2001;343:260-263.263ePaavola S, Zetterberg K, Privalov T, Csöregh I, Moberg C. Adv. Synth. Catal 2004;346:237-244.244fIwasawa T, Tokunaga M, Obora T, Tsuji Y. J. Am. Chem. Soc 2004;126:6554-6555.6555 [PubMed: 15161274]

28. For examples of Pd-catalyzed oxidative kinetic resolution, see:aFerreira EM, Stoltz BM. J. Am. Chem. Soc 2001;123:7725-7726.7726 [PubMed: 11481006]bBagdanoff JT, Ferreira EM, Stoltz BM. Org. Lett 2003;5:835-837.837 [PubMed: 12633084]cBagdanoff JT, Stoltz BM. Angew. Chem., Int. Ed 2004;43:353-357.357dCaspi DD, Ebner DC, Bagdanoff JT, Stoltz BM. Adv. Synth. Catal 2004;346:185-189.189eJensen DR, Pugsley JS, Sigman MS. J. Am. Chem. Soc 2001;123:74757476.7476 [PubMed: 11472200]fJensen DR, Sigman MS. Org. Lett 2002;5:63-65.65 [PubMed: 12509891]gMandal SK, Jensen DR, Pugsley JS, Sigman MS. J. Org. Chem 2003;68:4600-4603.4603 [PubMed: 12762783]hMandal SK, Sigman MS. J. Org. Chem 2003;68:7535-7537.7537 [PubMed: 12968915]

29. a Nishimura T, Onoue T, Ohe K, Uemura S. Tetrahedron Lett 1999;39:6011-6014. b Nishimura T, Onoue T, Ohe K, Uemura S. J. Org. Chem 1999;64:6750-6755. [PubMed: 11674682] c Nishimura T, Maeda Y, Kakiuchi N, Uemura S. J. Chem. Soc., Perkin Trans. 1 2000:4301-4305. d Kakiuchi N, Nishimura T, Inoue M, Uemura S. Bull. Chem. Soc. Jpn 2001;74:165-172. e Kakiuchi N, Maeda Y, Nishimura T, Uemura S. J. Org. Chem 2001;66:6620-6625. [PubMed: 11578212] 
30. a ten Brink G-J, Arends IWCE, Sheldon RA. Science 2000;287:1636-1639. [PubMed: 10698735] b ten Brink G-J, Arends IWCE, Hoogenraad M, Verspui G, Sheldon RA. Adv. Synth. Catal 2003;345:1341-1352.

31. Uemura's system has also been applied to other oxidation reactions: For a review, see: aNishimura T, Ohe K, Uemura S. Synlett 2004:201-216.216 For ring opening of hydroxycyclopropanes, see: bPark S-B, Cha JK. Org. Lett 2000;2:147-149.149 [PubMed: 10814268] For intramolecular oxidative amination, see: cFix SR, Brice JL, Stahl SS. Angew. Chem., Int. Ed 2002;41:164-166.166 For Wacker cyclizations, see: dTrend RM, Ramtohul YK, Ferreira EM, Stoltz BM. Angew. Chem., Int. Ed 2003;42:2892-2895.2895 For annulation of indoles, see: eFerreira EM, Stoltz BM. J. Am. Chem. Soc 2003;125:9578-9579.9579 [PubMed: 12904010]

32. Schultz MJ, Park CC, Sigman MS. Chem. Commun 2002:3034-3035.

33. For mechanistic studies on Pd(II)-catalyzed aerobic alcohol oxidations, see:aSteinhoff BA, Fix SR, Stahl SS. J. Am. Chem. Soc 2002;124:766-767.767 [PubMed: 11817948]bSteinhoff BA, Stahl SS. Org. Lett 2002;4:4179-4181.4181 [PubMed: 12423116]cMueller JA, Jensen DR, Sigman MS. J. Am. Chem. Soc 2002;124:8202-8203.8203 [PubMed: 12105896]dten Brink G-J, Arends IWCE, Sheldon RA. Adv. Synth. Catal 2002;344:355-369.369eten Brink G-J, Arends IWCE, Hoogenraad M, Verspui G, Sheldon RA. Adv. Synth. Catal 2003;345:497-505.505fMueller JA, Sigman MS. J. Am. Chem. Soc 2003;125:7005-7013.7013 [PubMed: 12783555] gNielson RJ, Keith JM, Stoltz BM, Goddard WA III. J. Am. Chem. Soc 2004;126:7967-7974.7974 [PubMed: 15212546]hSteinhoff BA, Guzei IA, Stahl SS. J. Am. Chem. Soc 2004;126:11268-11278.11278 [PubMed: 15355108]iMueller JA, Goller CP, Sigman MS. J. Am. Chem. Soc 2004;126:9724-9734.9734 [PubMed: 15291576] jKonnick MM, Guzei IA, Stahl SS. J. Am. Chem. Soc 2004;126:10212-10213.10213 [PubMed: 15315411]

34. Jensen DR, Schultz MJ, Mueller JA, Sigman MS. Angew. Chem., Int. Ed 2003;42:3810-3813.

35 . This was previously illustrated by showing that the addition of cinnamaldehyde inhibited the oxidation of 2-decanol. See ref 32 for details.

36. Mueller, JA.; Heaton, AL.; Sigman, MS. Unpublished results

37. For a recent review, see: Arterburn JB. Tetrahedron 2001;57:9765-9788.9788 
Oxidation of Benzylic Alcohols ${ }^{a}$

TABLE 1

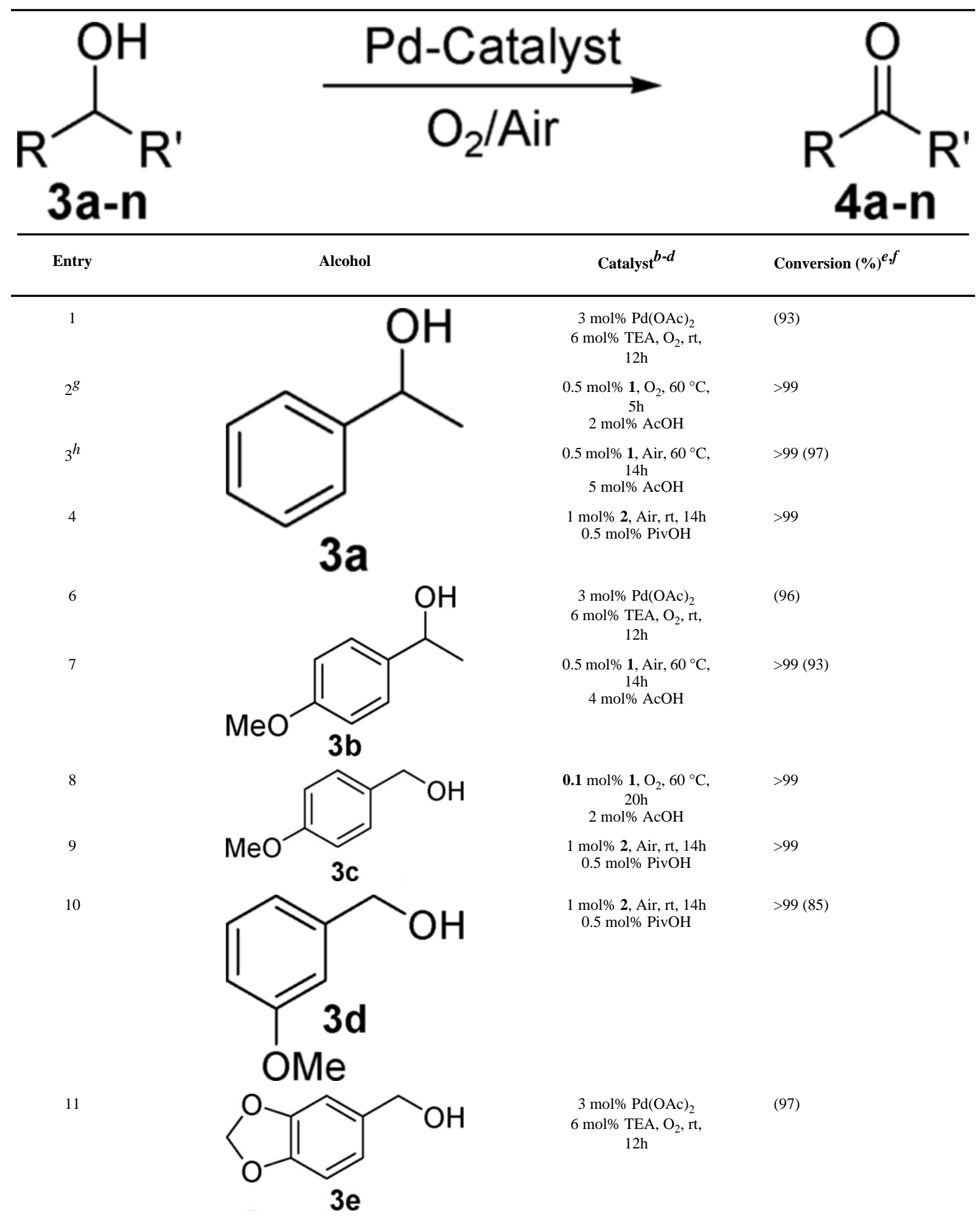




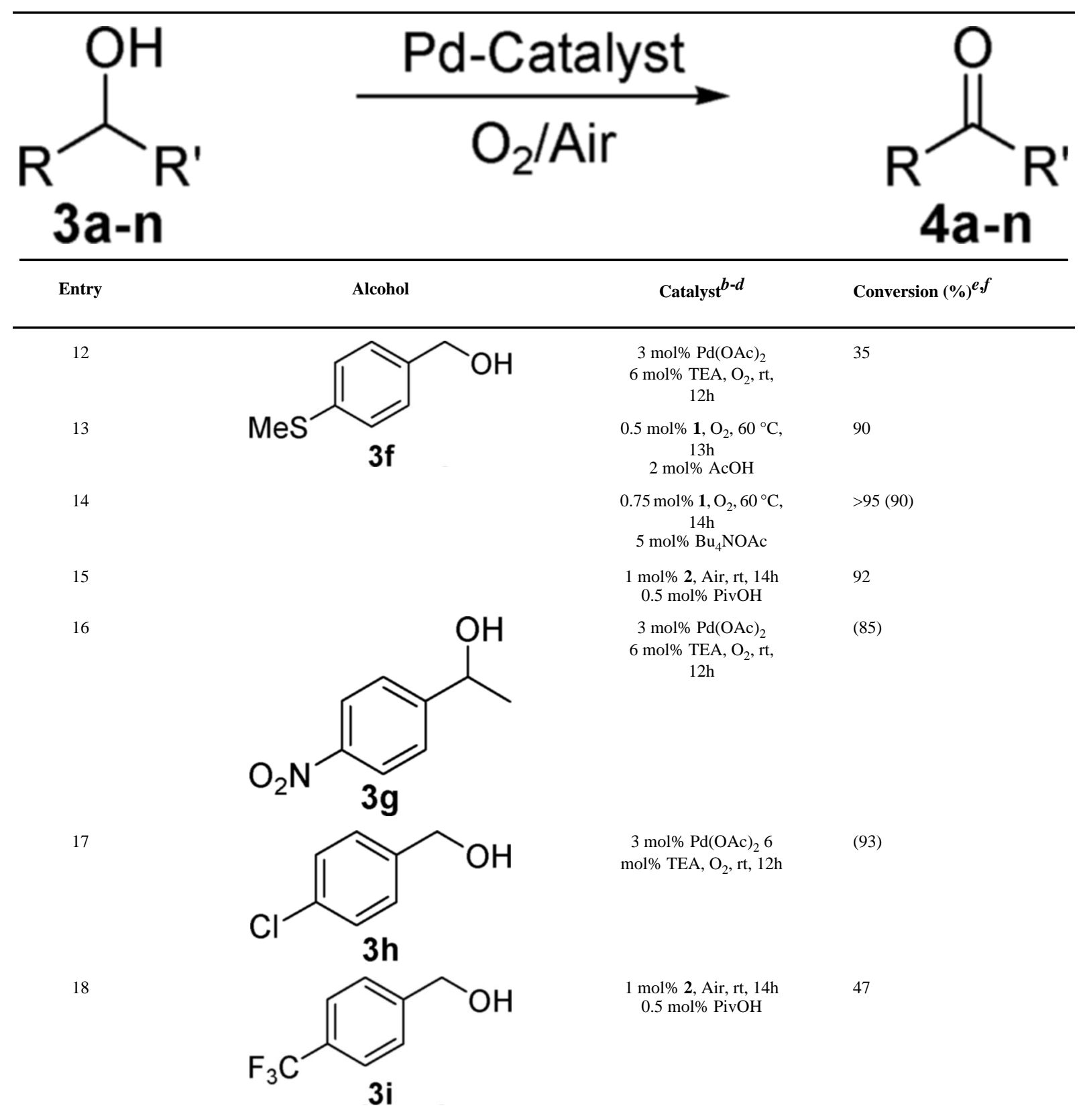




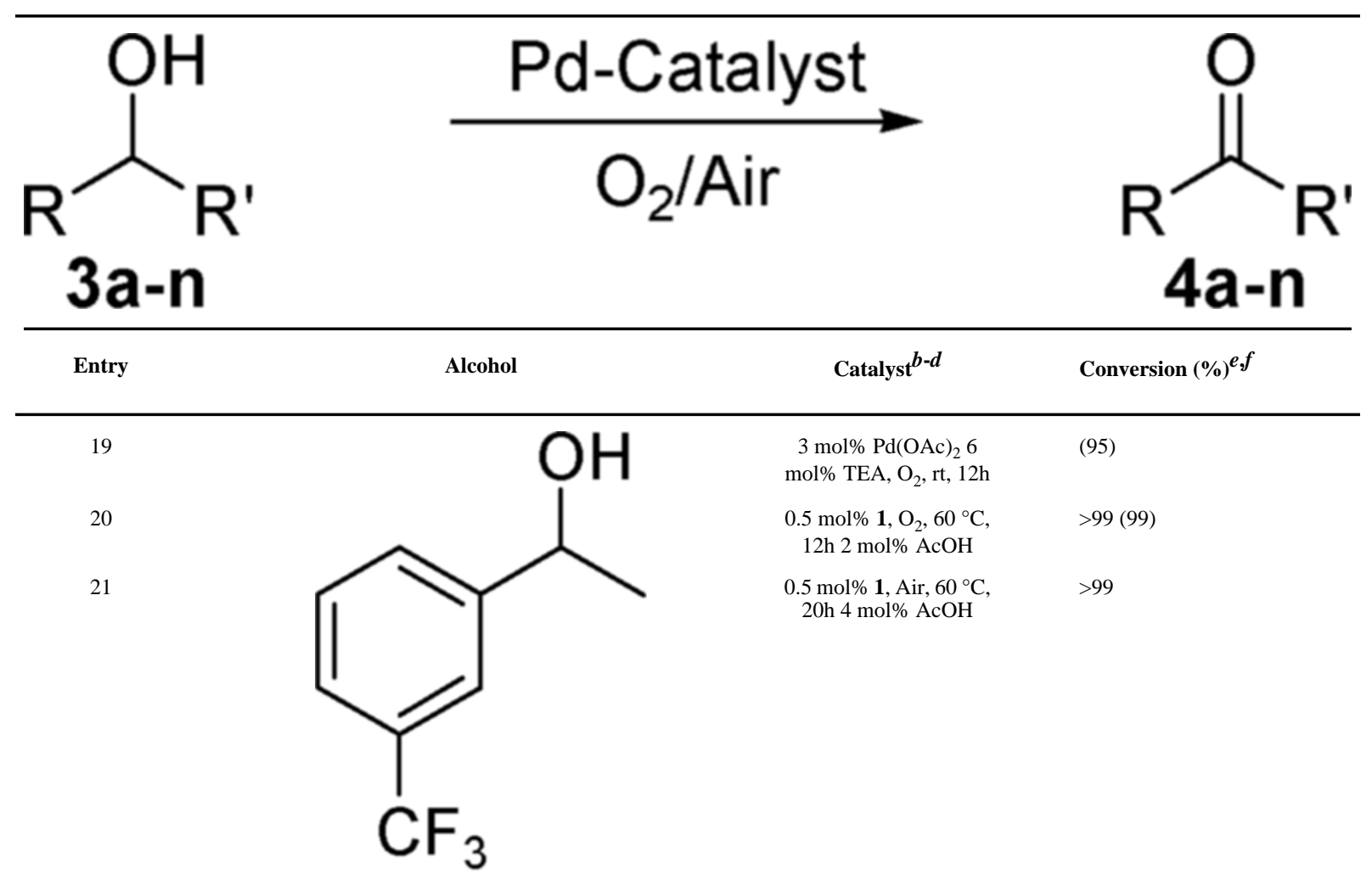

22

23

24

25

26

27 3j

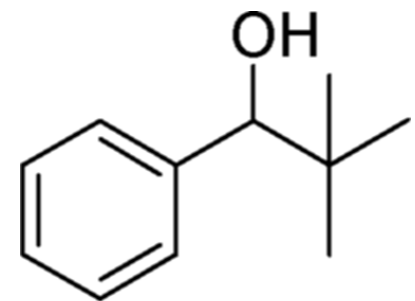

$3 k$

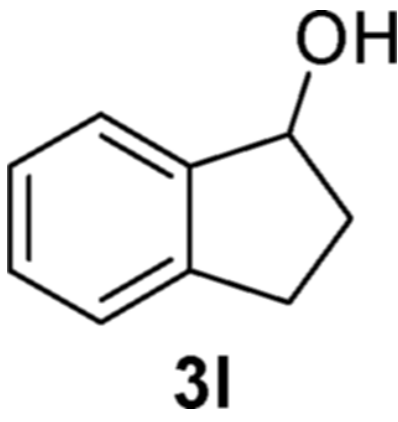

$3 \mathrm{~mol} \% \mathrm{Pd}(\mathrm{OAc})_{2} 6$ mol $\%$ TEA, $\mathrm{O}_{2}, \mathrm{rt}, 12 \mathrm{~h}$

$0.75 \mathrm{~mol} \% 1, \mathrm{O}_{2}, 60^{\circ} \mathrm{C}$,

14h $5 \mathrm{~mol} \% \mathrm{Bu}_{4} \mathrm{NOAc}$

$1 \mathrm{~mol} \%$ 2, Air, rt, $14 \mathrm{~h}$

$0.5 \mathrm{~mol} \% \mathrm{PivOH}$

$3 \mathrm{~mol} \% \mathrm{Pd}(\mathrm{OAc})_{2} 6$ $\mathrm{mol} \%$ TEA, $\mathrm{O}_{2}, \mathrm{rt}, 12 \mathrm{~h}$

$0.5 \mathrm{~mol} \% \mathrm{1}$, Air, $60^{\circ} \mathrm{C}$, $14 \mathrm{~h} 4 \mathrm{~mol} \% \mathrm{AcOH}$

$1 \mathrm{~mol} \%$ 2, Air, rt, $12 \mathrm{~h}$

$0.5 \mathrm{~mol} \% \mathrm{PivOH}$
(50)

91

23

(95)

$>99$

$>99$ 


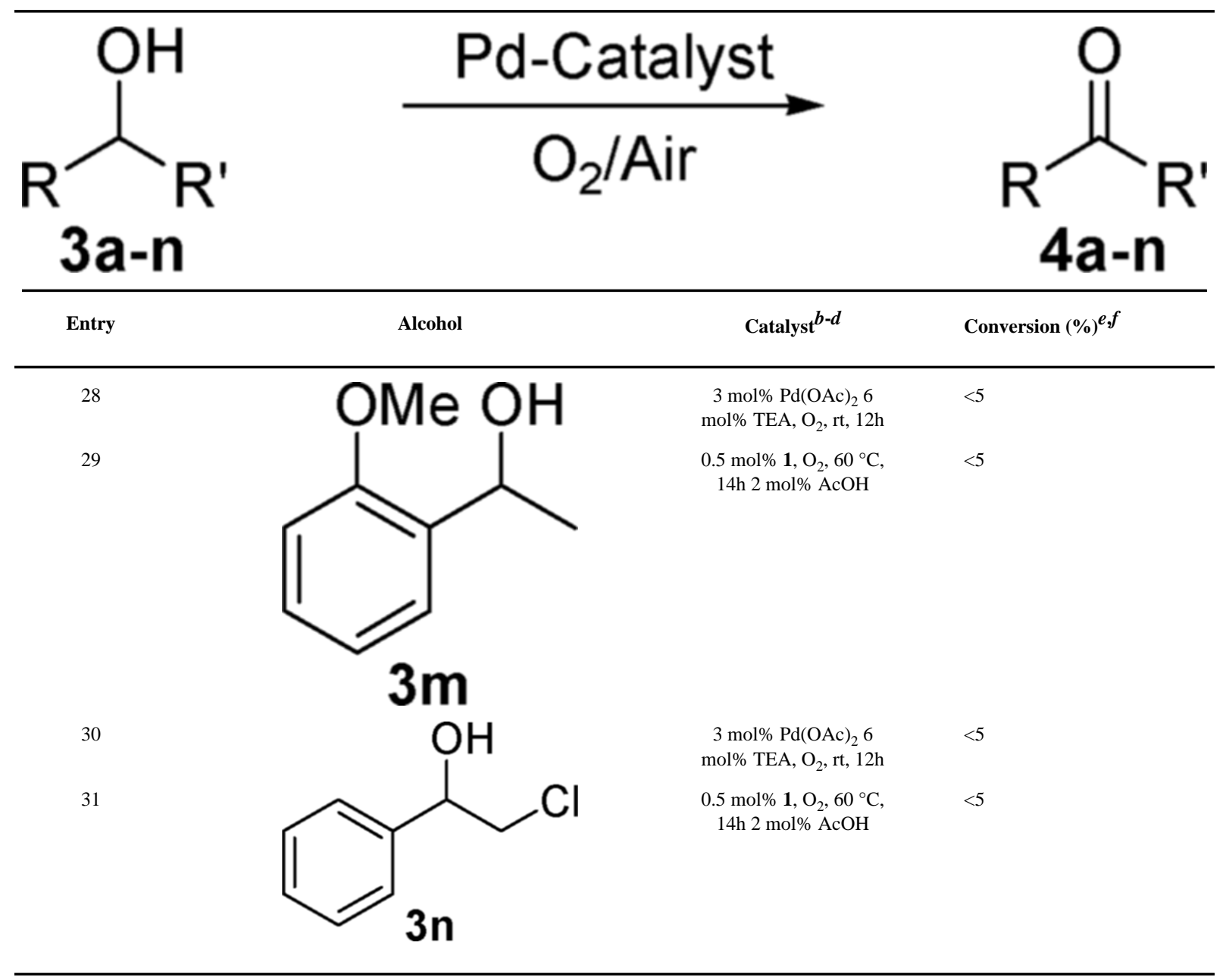

${ }^{a}$ See Experimental Section for details.

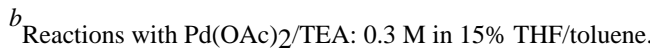

${ }^{c}$ Reactions with 1: $0.5 \mathrm{M}$ in toluene.

$d_{\text {Reactions with 2: } 0.4 \mathrm{M} \text { in toluene. }}$

${ }^{e}$ Conversion measured by GC or ${ }^{1} \mathrm{H}$ NMR.

$f_{\text {Isolated yield in parentheses. }}$

${ }^{g}$ Catalyst 1 prepared in situ with $0.5 \mathrm{~mol} \%$ of $\mathrm{Pd}(\mathrm{OAc})_{2}, 0.65 \mathrm{~mol} \%$ of $\mathrm{IiPr}-\mathrm{HBF} 4$, and $0.7 \mathrm{~mol} \%$ of KO ${ }^{t} \mathrm{Bu}$.

$h_{1.0-\mathrm{g} \text { scale. }}$ 
TABLE 2

Oxidation of Aliphatic and Allylic Alcohols ${ }^{a}$
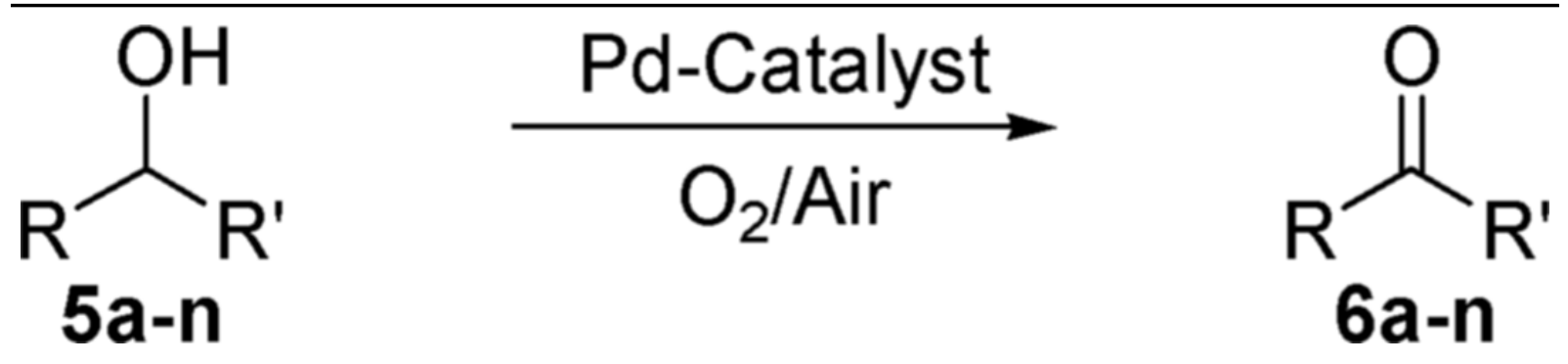

\begin{tabular}{|c|c|c|c|}
\hline Entry & Alcohol & Catalyst $^{b-e}$ & Conversion $(\%)^{f, g}$ \\
\hline 1 & $\begin{array}{c}\text { 2-decanol } \\
\mathbf{5 a}\end{array}$ & $\begin{array}{c}3 \mathrm{~mol} \% \mathrm{Pd}(\mathrm{OAc})_{2} \\
6 \mathrm{~mol} \% \text { TEA, } \mathrm{O}_{2}, \mathrm{rt} \\
12 \mathrm{~h}\end{array}$ & (97) \\
\hline
\end{tabular}

2

$0.5 \mathrm{~mol} \% 1, \mathrm{O}_{2}, 60{ }^{\circ} \mathrm{C}$

99 (93)

$$
1 \mathrm{~mol} \% \mathrm{AcOH}
$$

3

$1 \mathrm{~mol} \%$ 2, Air, rt, $14 \mathrm{~h}$

97

$0.5 \mathrm{~mol} \% \mathrm{PivOH}$

(98)

$3 \mathrm{~mol} \% \mathrm{Pd}(\mathrm{OAc})_{2}$ $6 \mathrm{~mol} \%$ TEA, rt, $\mathrm{O}_{2}$,

$12 \mathrm{~h}$

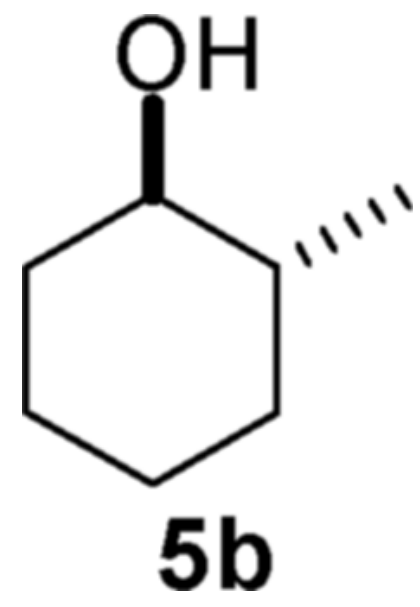

$3 \mathrm{~mol} \% \mathrm{Pd}(\mathrm{OAc})_{2}$ $6 \mathrm{~mol} \%$ TEA, $\mathrm{O}_{2}$, rt,

(81)

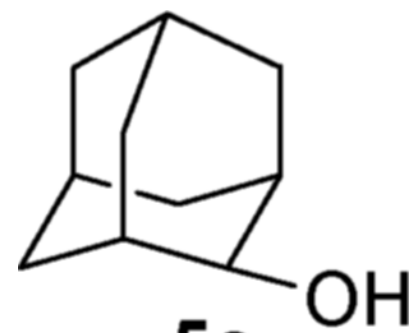

$12 \mathrm{~h}$

5

5c

$6^{h}$

$3 \mathrm{~mol} \% \mathrm{Pd}(\mathrm{OAc})_{2}$
$6 \mathrm{~mol} \%$ TEA, $\mathrm{O}_{2}, \mathrm{rt}$,
$12 \mathrm{~h}$

(90)

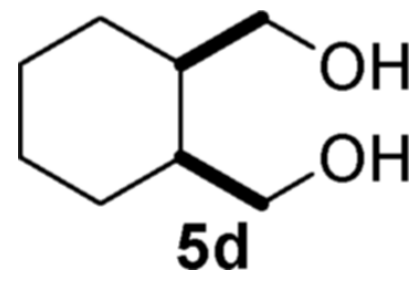




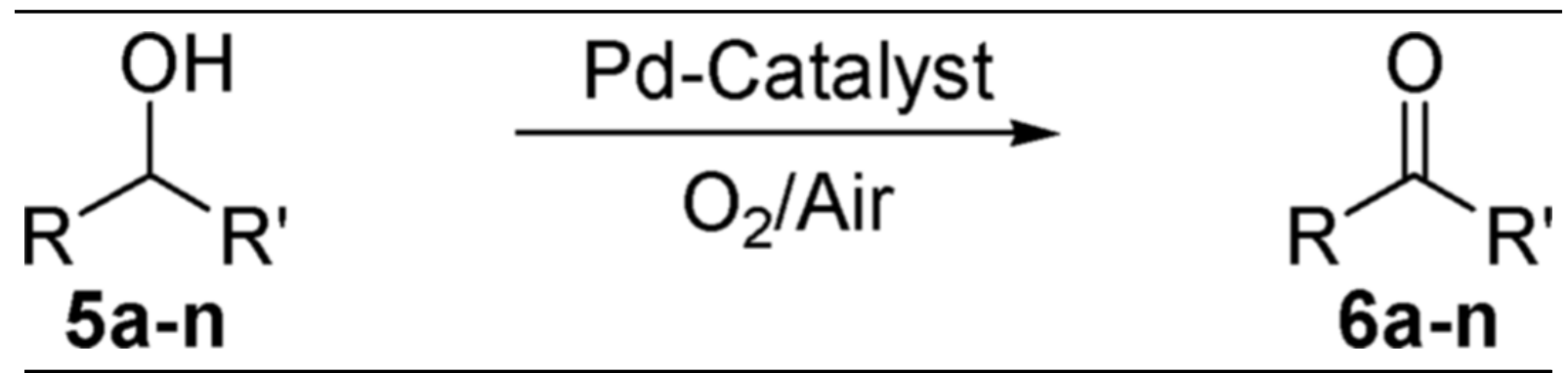

\begin{tabular}{|c|c|c|c|}
\hline Entry & Alcohol & Catalyst $^{b-e}$ & Conversion $(\%)^{f, g}$ \\
\hline 7 & & $\begin{array}{c}0.5 \mathrm{~mol} \% \mathrm{1}, \mathrm{O}_{2}, 60^{\circ} \mathrm{C} \\
13 \mathrm{~h} \\
1 \mathrm{~mol} \% \mathrm{AcOH}\end{array}$ & $>99$ \\
\hline 8 & & $\begin{array}{c}0.5 \mathrm{~mol} \% \mathrm{1} \text {, Air, } 60^{\circ} \mathrm{C} \\
14 \mathrm{~h} \\
2 \mathrm{~mol} \% \mathrm{AcOH}\end{array}$ & 96 \\
\hline 9 & & $\begin{array}{c}1 \mathrm{~mol} \% \mathrm{2}, \mathrm{Air}, \mathrm{rt}, 14 \mathrm{~h} \\
0.5 \mathrm{~mol} \% \mathrm{PivOH}\end{array}$ & 63 \\
\hline 10 & & $\begin{array}{c}1 \mathrm{~mol} \% \text { 2, Air, rt, } 14 \mathrm{~h} \\
0.5 \mathrm{~mol} \% \mathrm{PivOH}\end{array}$ & $>99$ (89) \\
\hline $11^{i}$ & $\begin{array}{l}\text { 1-dodecanol } \\
\mathbf{5 g}\end{array}$ & $\begin{array}{c}3 \mathrm{~mol} \% \mathrm{Pd}(\mathrm{OAc})_{2} \\
18 \mathrm{~mol} \% \mathrm{TEA}, \mathrm{O}_{2}, \mathrm{rt} \\
12 \mathrm{~h}\end{array}$ & (85) \\
\hline 12 & & $\begin{array}{c}0.5 \mathrm{~mol} \% \mathrm{1}, \mathrm{O}_{2}, 60^{\circ} \mathrm{C} \\
10 \mathrm{~h} \\
5 \mathrm{~mol} \% \mathrm{Bu}_{4} \mathrm{NOAc}\end{array}$ & $85(76)$ \\
\hline 13 & $\begin{array}{l}\text { 1-octadecanol } \\
\mathbf{5 h}\end{array}$ & $\begin{array}{c}0.5 \mathrm{~mol} \% \mathrm{1}, \mathrm{O}_{2}, 60^{\circ} \mathrm{C} \\
10 \mathrm{~h} \\
5 \mathrm{~mol} \% \mathrm{Bu}_{4} \mathrm{NOAc}\end{array}$ & (85) \\
\hline 14 & & $\begin{array}{c}0.5 \mathrm{~mol} \% \mathrm{1}, \mathrm{O}_{2}, 60{ }^{\circ} \mathrm{C} \\
12 \mathrm{~h} \\
2 \mathrm{~mol} \% \mathrm{AcOH}\end{array}$ & $91(84)$ \\
\hline 15 & & $\begin{array}{c}1 \mathrm{~mol} \% 2, \text { Air, rt, } 14 \mathrm{~h} \\
0.5 \mathrm{~mol} \% \mathrm{PivOH}\end{array}$ & 62 \\
\hline
\end{tabular}




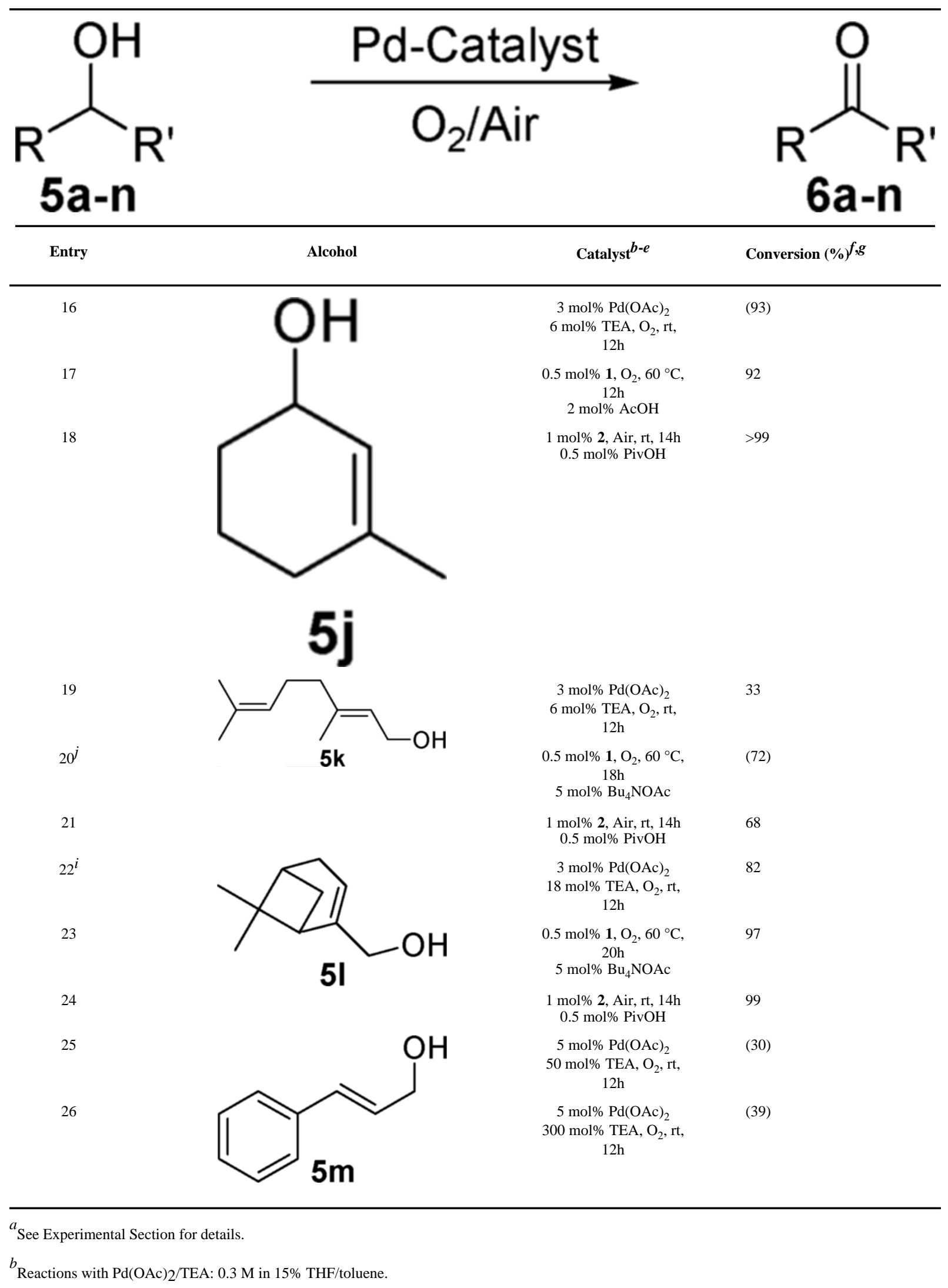

J Org Chem. Author manuscript; available in PMC 2009 June 8. 
${ }^{c}$ Reactions with $\mathbf{1}$ and secondary alcohols: $0.5 \mathrm{M}$ in toluene.

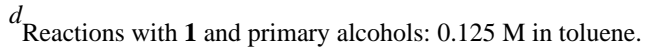

${ }^{e}$ Reactions with 2: $0.4 \mathrm{M}$ in toluene.

$f_{\text {Conversion measured by GC or }}{ }^{1} \mathrm{H}$ NMR.

${ }^{g}$ Isolated yield in parentheses.

$h_{\text {Product is the corresponding lactone. }}$

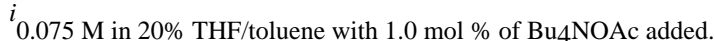

$j_{5.4: 1 \text { mixture of isomers measured by }{ }^{1} \mathrm{H} \text { NMR. }}$ 
Oxidation of 1,3 Monoprotected Diols

TABLE 3
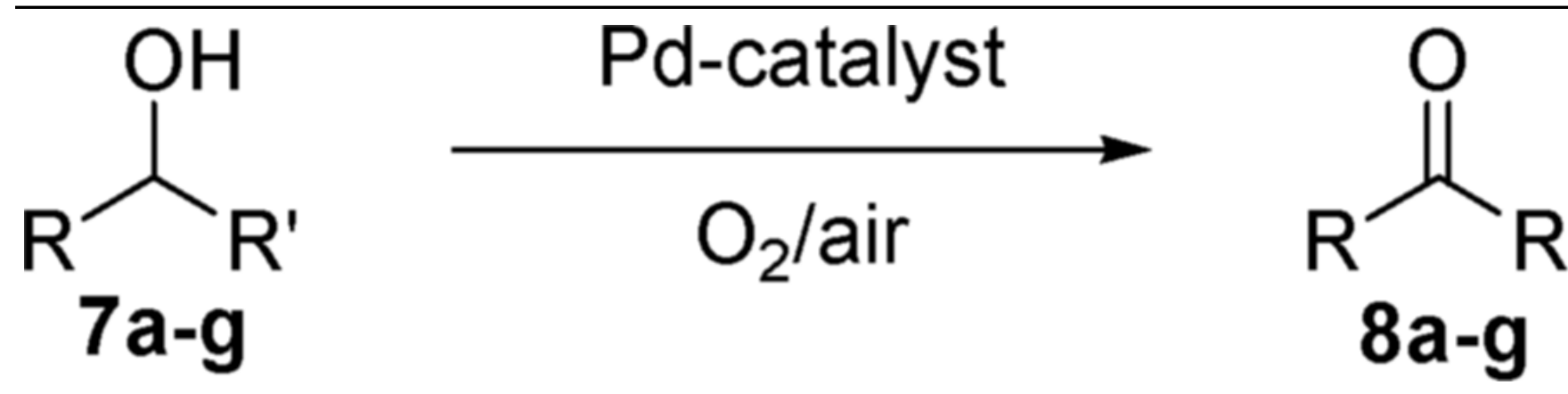

\begin{tabular}{|c|c|c|c|c|}
\hline Entry & Substrate & Catalyst $^{a-d}$ & Time (h) & Yield $(\%)^{e}$ \\
\hline 1 & & $\begin{array}{c}4 \mathrm{~mol} \% \mathrm{Pd}(\mathrm{OAc})_{2} \\
8 \mathrm{~mol} \% \text { TEA, } \mathrm{O}_{2}, \mathrm{rt}\end{array}$ & 12 & $>99$ (95) \\
\hline 2 & & $\begin{array}{c}1 \mathrm{~mol} \% 1, \mathrm{O}_{2}, 60^{\circ} \mathrm{C} \\
1 \mathrm{~mol} \% \mathrm{AcOH}\end{array}$ & 14 & 93 \\
\hline 3 & & $\begin{array}{l}1 \mathrm{~mol} \% 2 \text {, Air, rt } \\
0.5 \mathrm{~mol} \% \mathrm{PivOH}\end{array}$ & 13 & 80 \\
\hline
\end{tabular}

$7 a$

$\mathrm{P}=\mathrm{Ac}$

$7 \mathbf{b}$

$5 \mathrm{~mol} \% \mathrm{Pd}(\mathrm{OAc})_{2}$

18

$>99$ (92)

5

$1 \mathrm{~mol} \% \mathrm{1}, \mathrm{O}_{2}, 60{ }^{\circ} \mathrm{C}$

$1 \mathrm{~mol} \% \mathrm{AcOH}$

$1 \mathrm{~mol} \% 2$, Air, rt $0.5 \mathrm{~mol} \% \mathrm{PivOH}$

$5 \mathrm{~mol} \% \mathrm{Pd}(\mathrm{OAc})_{2}$

$10 \mathrm{~mol} \%$ TEA, $\mathrm{O}_{2}$, rt

$0.5 \mathrm{~mol} \% \mathrm{1}, \mathrm{O}_{2}, 60{ }^{\circ} \mathrm{C}$

$1 \mathrm{~mol} \% \mathrm{AcOH}$

$1 \mathrm{~mol} \% 2$, Air, rt $0.5 \mathrm{~mol} \% \mathrm{PivOH}$

$4 \mathrm{~mol} \% \mathrm{Pd}(\mathrm{OAc})_{2}$

$8 \mathrm{~mol} \%$ TEA, $\mathrm{O}_{2}$, rt

$0.5 \mathrm{~mol} \% \mathrm{1}, \mathrm{O}_{2}, 60{ }^{\circ} \mathrm{C}$

$1 \mathrm{~mol} \% \mathrm{AcOH}$

$1 \mathrm{~mol} \%$ 2, Air, rt $0.5 \mathrm{~mol} \% \mathrm{PivOH}$<smiles>CCCC(C[OH+])C(O)C(C)C</smiles>

$5 \mathrm{~mol} \% \mathrm{Pd}(\mathrm{OAc})_{2}$

$10 \mathrm{~mol} \%$ TEA, $\mathrm{O}_{2}$, rt

$0.5 \mathrm{~mol} \% \mathrm{1}, \mathrm{O}_{2}, 60{ }^{\circ} \mathrm{C}$

$1 \mathrm{~mol} \% \mathrm{AcOH}$

$1 \mathrm{~mol} \% 2$, Air, rt $0.5 \mathrm{~mol} \% \mathrm{PivOH}$ 


\begin{tabular}{|c|c|c|c|c|}
\hline Entry & Substrate & Catalyst $^{a-d}$ & Time (h) & Yield $(\%)^{e}$ \\
\hline $16^{h}$ & & $\begin{array}{c}5 \mathrm{~mol} \% \mathrm{Pd}(\mathrm{OAc})_{2} \\
10 \mathrm{~mol} \% \mathrm{TEA} \\
1 \mathrm{~mol} \% \mathrm{Bu}_{4} \mathrm{NOAc} \\
\mathrm{O}_{2}, \mathrm{rt}\end{array}$ & 12 & (91) \\
\hline 17 & & $\begin{array}{c}1 \mathrm{~mol} \% 1, \mathrm{O}_{2}, 60^{\circ} \mathrm{C} \\
5 \mathrm{~mol} \% \mathrm{Bu}_{4} \mathrm{NOAc}\end{array}$ & 13 & 94 \\
\hline $18^{h}$ & & $\begin{array}{c}4 \mathrm{~mol} \% \mathrm{Pd}(\mathrm{OAc})_{2} \\
24 \mathrm{~mol} \% \mathrm{TEA} \\
1 \mathrm{~mol} \% \mathrm{Bu}_{4} \mathrm{NOAc} \\
\mathrm{O}_{2}, \mathrm{rt}\end{array}$ & 15 & 69 \\
\hline 19 & & $\begin{array}{c}0.5 \mathrm{~mol} \% 1, \mathrm{O}_{2}, 60^{\circ} \mathrm{C} \\
5 \mathrm{~mol} \% \mathrm{Bu}_{4} \mathrm{NOAc}^{-}\end{array}$ & 15 & 46 \\
\hline
\end{tabular}

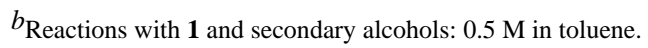

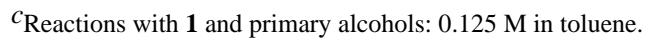

$f_{\text {Conversion measured by GC or }}{ }^{1} \mathrm{H}$ NMR.

${ }^{a}$ Reactions with $\mathrm{Pd}(\mathrm{OAc}) 2 / \mathrm{TEA}: 0.3 \mathrm{M}$ in $15 \% \mathrm{THF} /$ toluene.

$d_{\text {Reactions with 2: } 0.4 \mathrm{M} \text { in toluene. }}$

${ }^{e}$ Isolated yield in parentheses.

$g_{30-\mathrm{mmol} \text { scale. }}$

$h_{0.075 \mathrm{M} \text { in } 20 \% \mathrm{THF} / \text { toluene. }}$ 
TABLE 4

Oxidation of 1,2 Monoprotected Diols and Amino Alcohols

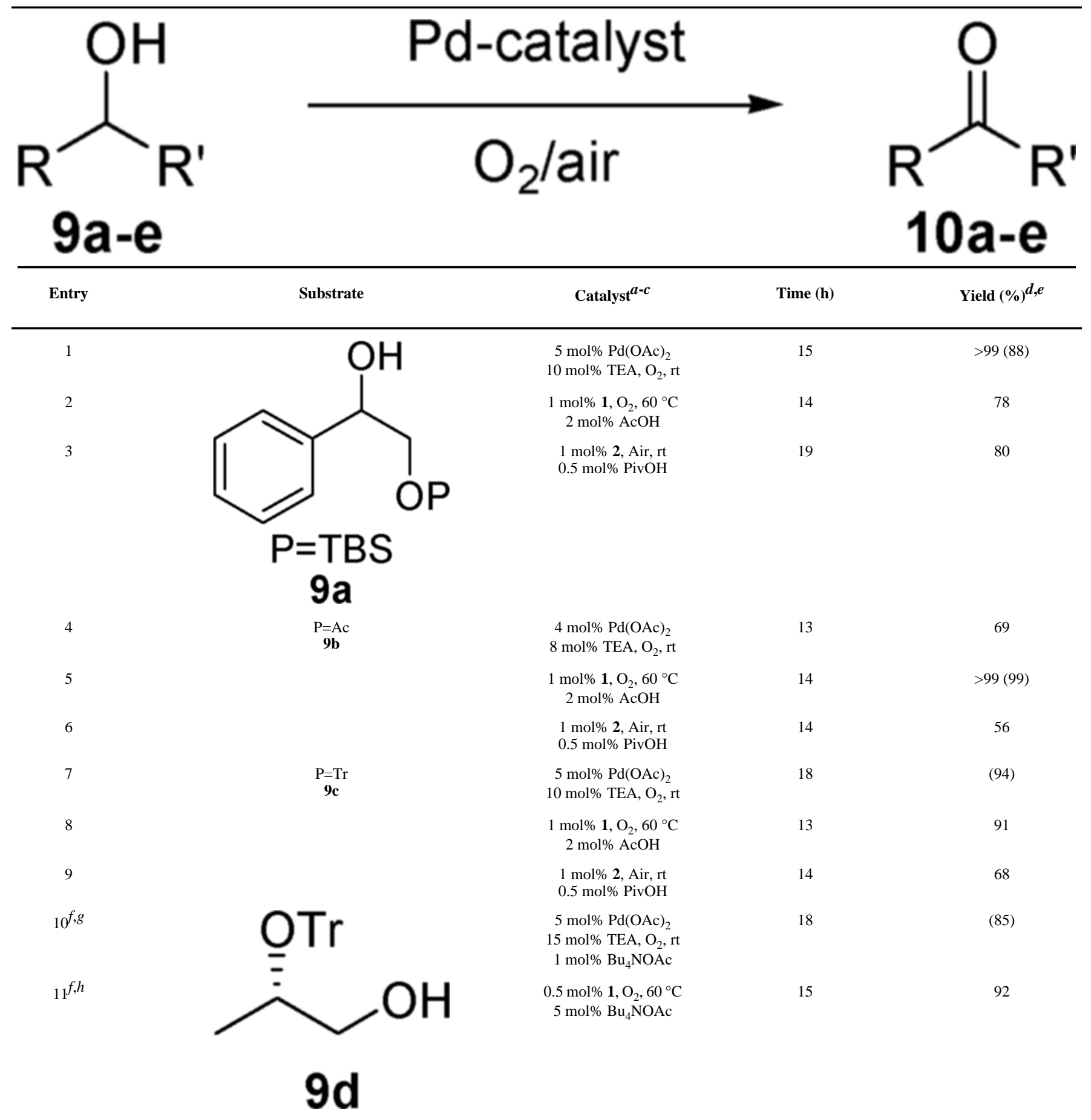




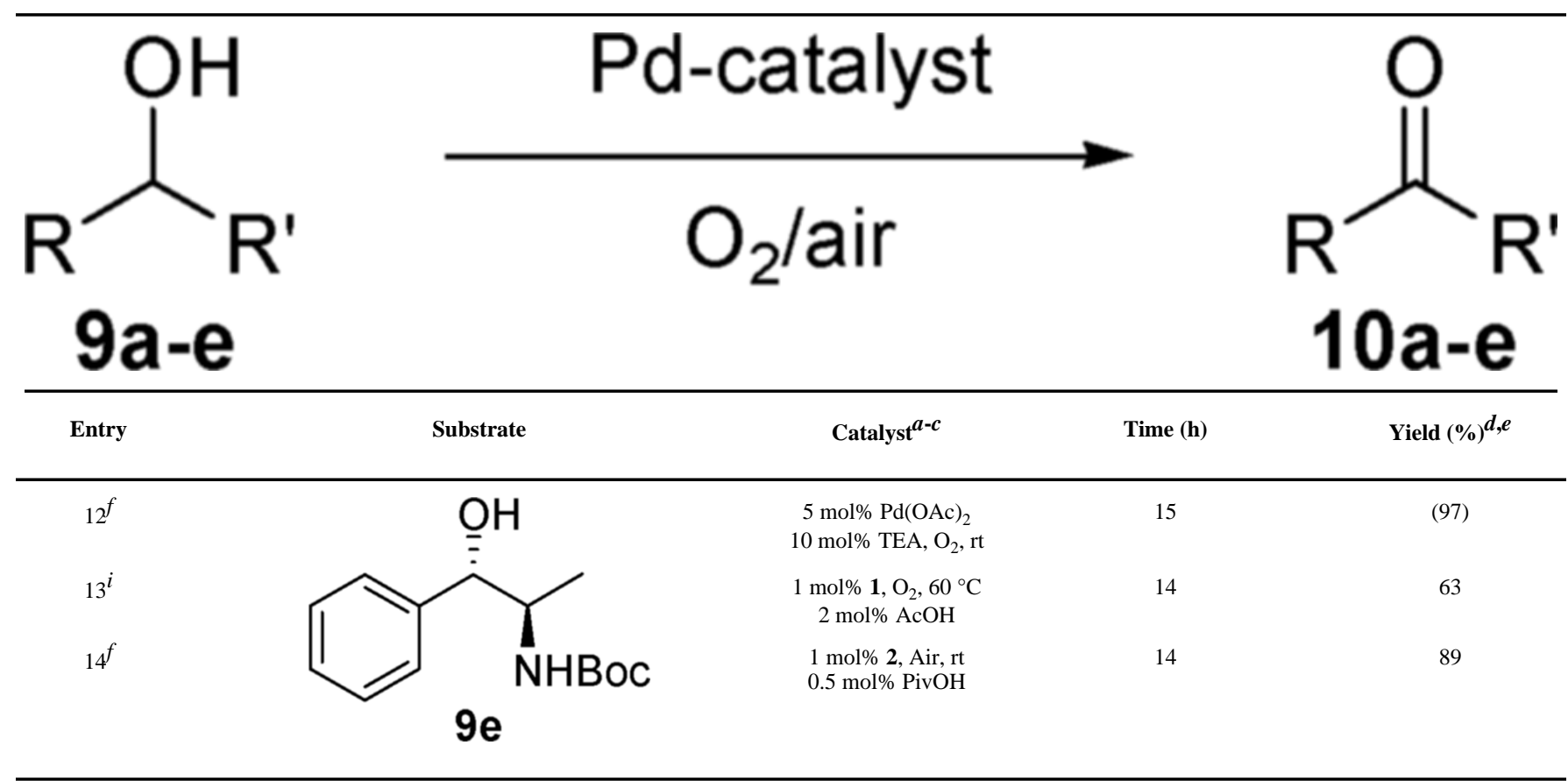

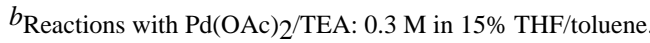

$a_{\text {Isolated yield in parentheses. }}$

${ }^{c}$ Reactions with 1: $0.5 \mathrm{M}$ in toluene.

$d_{\text {Reactions with 2: } 0.4 \mathrm{M} \text { in toluene. }}$

${ }^{e}$ Conversion measured by GC or by ${ }^{1} \mathrm{H}$ NMR.

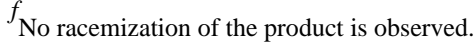

$g_{0.1 \mathrm{M} \text {. }}$

$h_{0.125 \mathrm{M} \text {. }}$

${ }^{i}$ Racemized from $99 \%$ to $97 \%$ ee. 
TABLE 5

Preventing Ester Formation of 1,2-Amino Alcohols

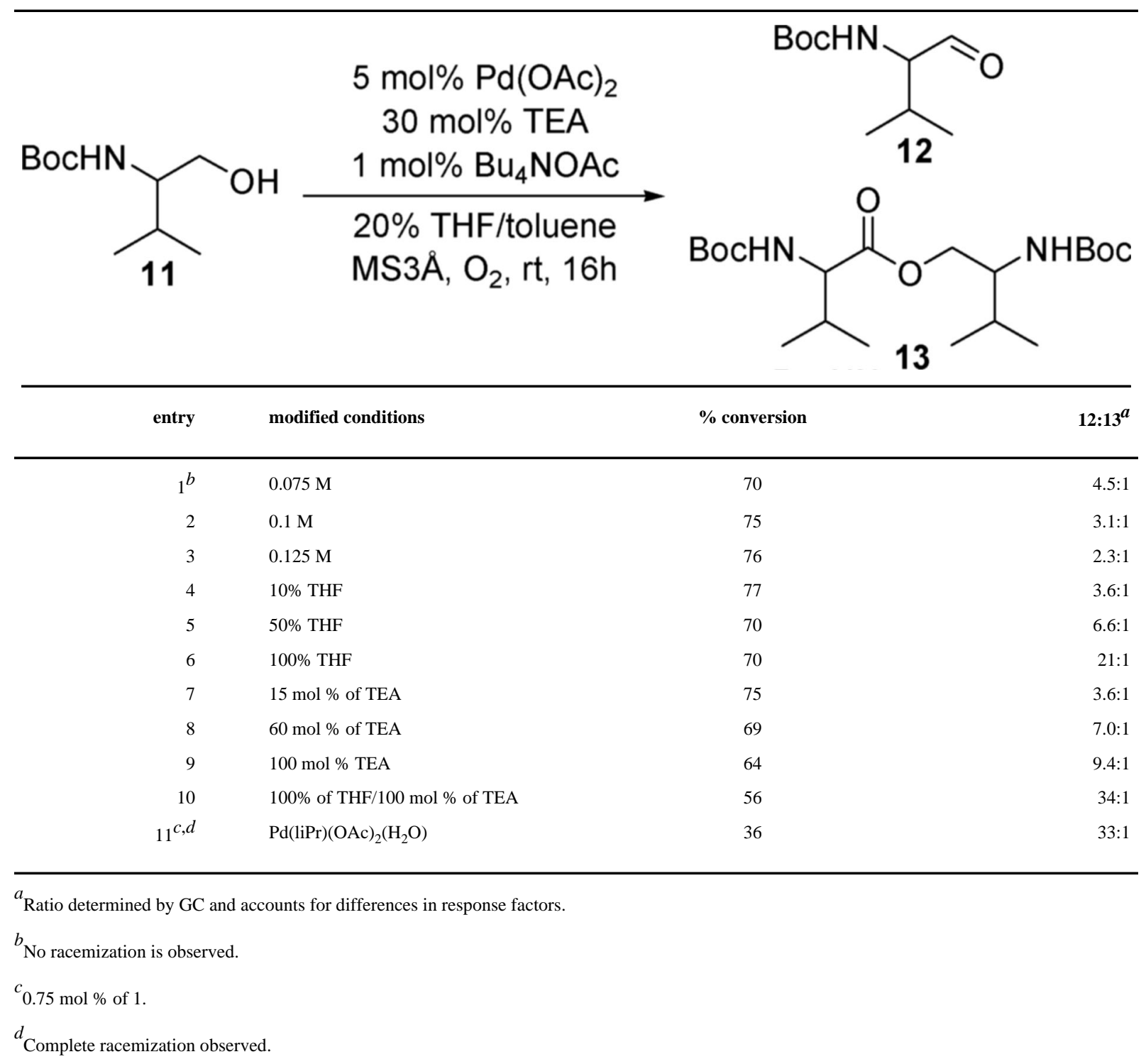




\section{Chemoselective Alcohol Oxidations}

TABLE 6

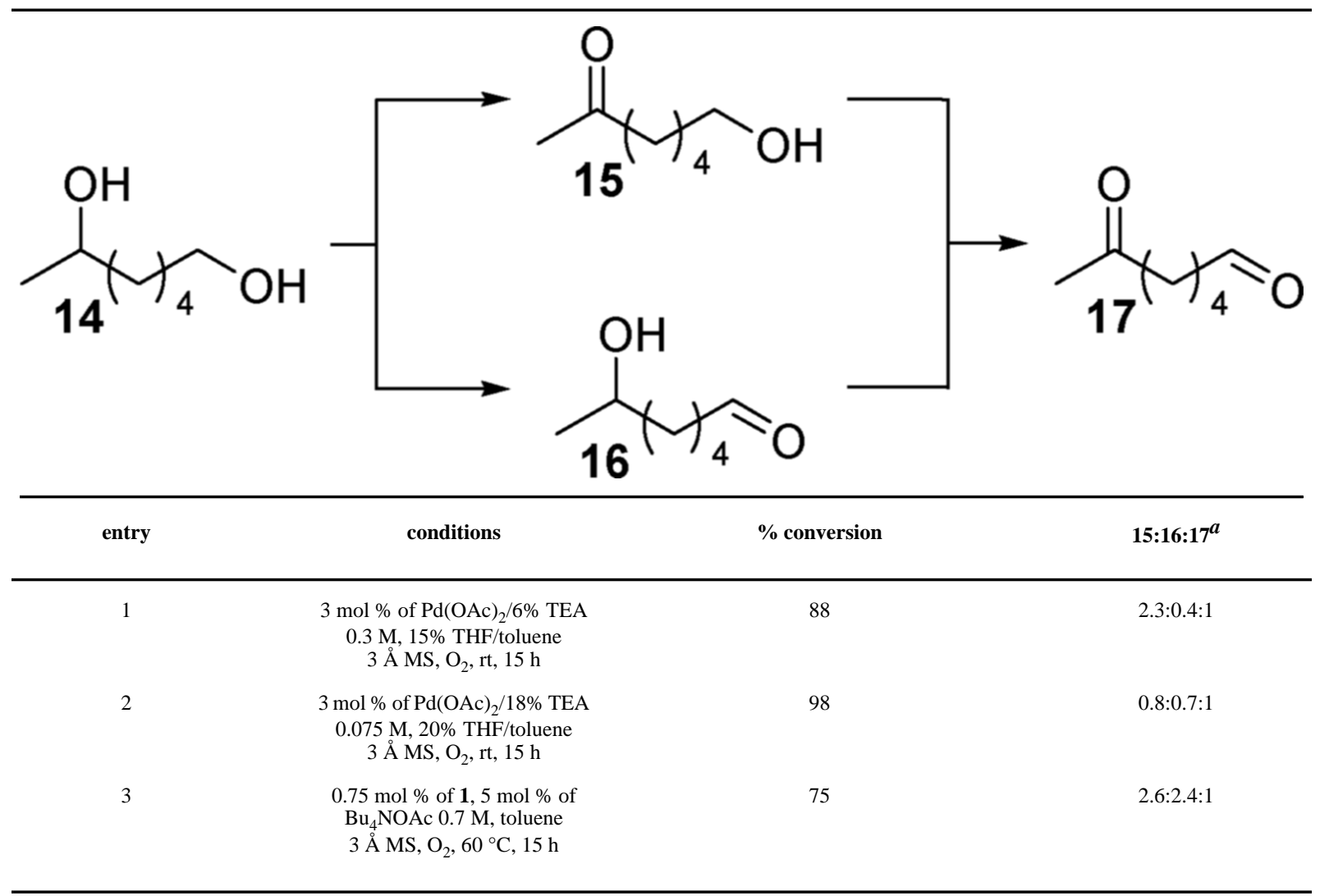

${ }^{a}$ Ratio determined by GC and does not account for differences in response factors. 


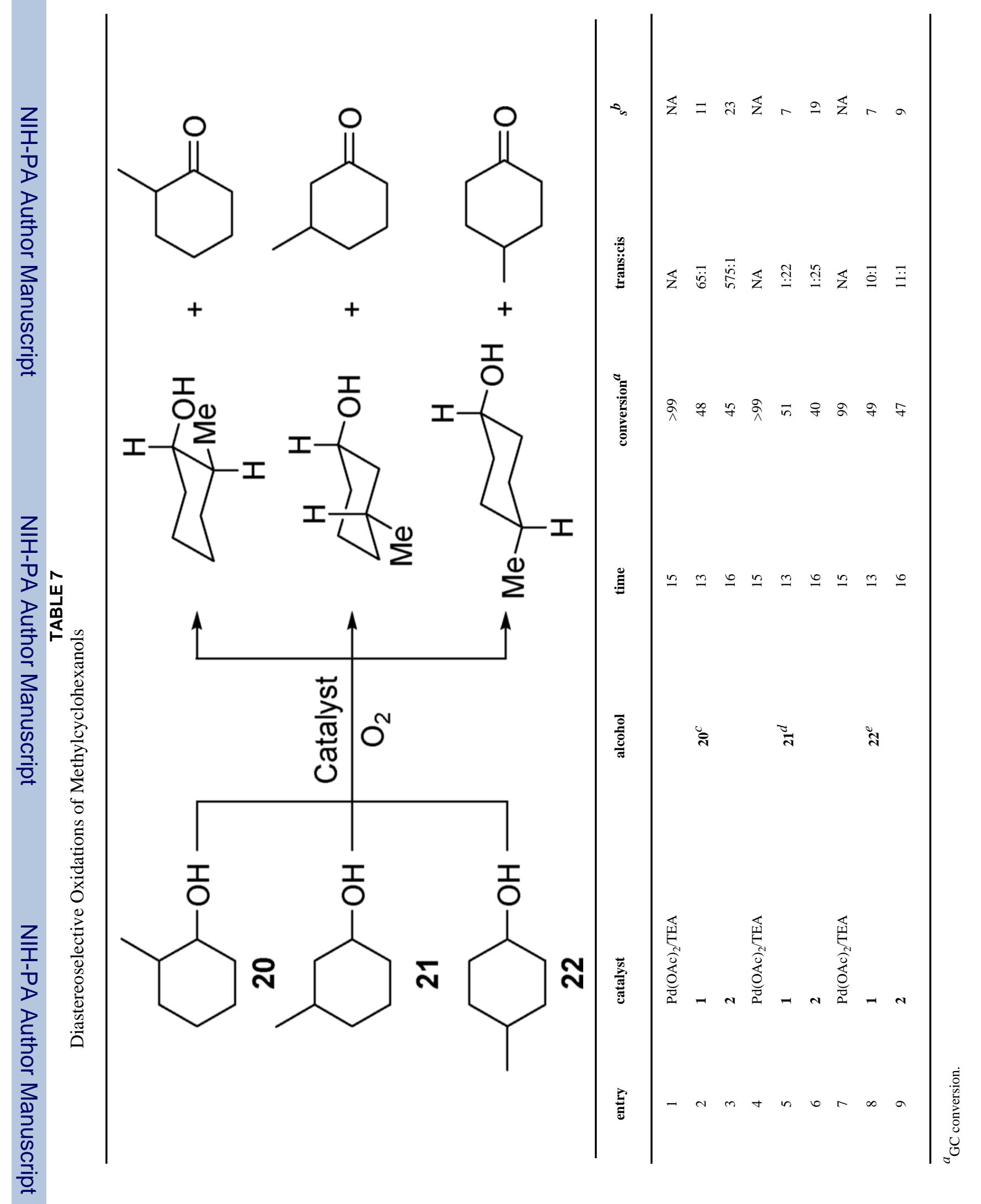

J Org Chem. Author manuscript; available in PMC 2009 June 8. 


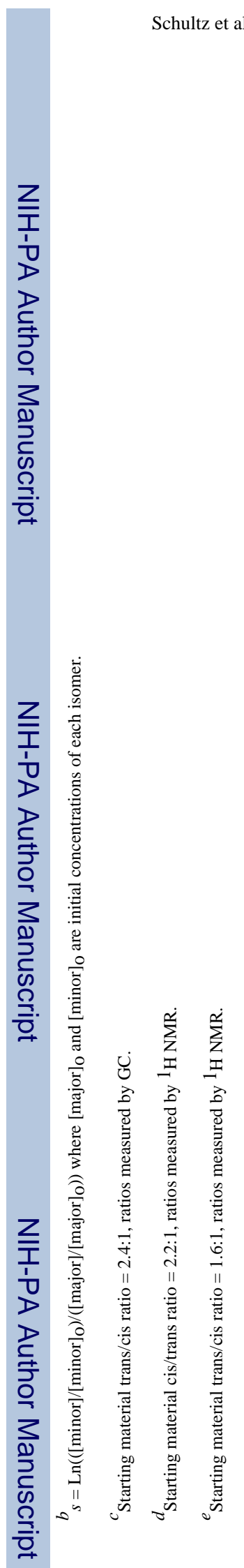

Page 29

J Org Chem. Author manuscript; available in PMC 2009 June 8. 